\title{
Nano-scale Mechanical Properties and Microstructure of Irradiated X-750 Ni-Based Superalloy
}

\author{
P. CHANGIZIAN, A. BROOKS, Z. YAO, and M.R. DAYMOND
}

This study investigates the effect of irradiation on the mechanical properties of a Ni-based superalloy, X-750. $40 \mathrm{MeV} \mathrm{Ni}^{+}$ions were used to irradiate the X-750 up to $1 \mathrm{dpa}$ with and without 5000 appm helium pre-implantation at room temperature and $400{ }^{\circ} \mathrm{C}$. Nano-indentation hardness tests were carried out at room temperature in the depth range of 200 to $1400 \mathrm{~nm}$ before and after irradiation. Cross-sectional TEM observations were performed on the irradiated materials to correlate the mechanical results with the microstructural evolution. The results show that helium pre-implantation enhances the irradiation-induced hardening due to generating a high density of small cavities and promoting the formation of larger Frank loops. In addition, nano-scale mechanical tests reveal that changing the subsequent $\mathrm{Ni}$ ion irradiation temperature from room temperature to $400{ }^{\circ} \mathrm{C}$, leads to changing of the mechanical response from a softening behavior to an irradiation-induced hardening. The $\gamma^{\prime}$ precipitates became disordered after irradiation at room temperature, whereas the $\gamma^{\prime}$-phase remained ordered during irradiation at $400{ }^{\circ} \mathrm{C}$. The softening effect of the $\gamma^{\prime}$ instability outweighed the hardening impact of irradiation-induced defects such as cavities and Frank loops, leading to a hardness reduction for the room-temperature-irradiated material. Three different obstacle-hardening models were employed to assess the individual impact of each type of defect on the material's overall strength enhancement. Furthermore, the superposition principle was used for each model to estimate the overall irradiation-induced strengthening, which is compared to the results from the nano-hardness measurements.

https://doi.org/10.1007/s11661-017-4445-7

(C) The Minerals, Metals \& Materials Society and ASM International 2017

\section{INTRODUCTION}

RADIATION damage in materials is a crucial concern in advanced and conventional nuclear reactors, spallation sources, isotope production facilities, and future fusion technology applications. Mechanical properties degradation and environmental interactions are key issues during lifetime extension or performance predictions for these types of systems. Thankfully, the effect of irradiation on the mechanical properties of structural materials in nuclear reactors has been the subject of intense studies over the past few decades. ${ }^{[1-4]}$ Such investigations have been inaugural to the worldwide effort to produce materials with greater resistance to the environmental effect of nuclear reactors for future designs. For this purpose, a deep understanding

P. CHANGIZIAN, A. BROOKS, Z. YAO, and M.R. DAYMOND are with the Department of Mechanical and Materials Engineering, Queen's University, Kingston K7L3N6, ON, Canada. Contact e-mail: yaoz@queensu.ca

Manuscript submitted August 29, 2017.

Article published online December 21, 2017 of the failure mechanisms through investigation of post-irradiation mechanical properties and microstructural changes in structural materials is of importance. Of our particular interest is the influence of radiation damage on Ni-based superalloys, such as Inconel $\mathrm{X}-750$ which is used as a critical component spacer material in the CANada Deuterium Uranium (CANDU) heavy water reactor. ${ }^{[5]}$ Post-irradiation mechanical examinations on X-750 spacers removed from CANDU reactors have revealed that they exhibit a reduction in ductility, which depends on operation temperature, as well as lower load carrying capacity compared to the as-installed condition. ${ }^{[6]}$ Although the underlying mechanism leading to the mechanical properties degradation is not yet fully understood, some studies have been carried out on the microstructural changes of ex-service (neutron-irradiated) spacers. ${ }^{[5,7,8]}$ Furthermore, some studies have tried to emulate the effect of neutron irradiation on the microstructure of X-750 alloy by means of employing heavy ion irradiation under controlled irradiation conditions. ${ }^{[9-11]}$ The results show that irradiation may affect the microstructure in different ways depending on irradiation temperature, irradiation dose, and dose rate. 
$\mathrm{X}-750$ is an age-hardened Ni-based superalloy strengthened by precipitation of the $\gamma^{\prime}-\mathrm{Ni}_{3}$ (Ti, Al) phase with an $\mathrm{L1}_{2}$-ordered structure. ${ }^{[12]}$ However, the strengthening precipitate is susceptible to phase instability under irradiation environments. Zhang et al. ${ }^{[10]}$ investigated the stability of the $\gamma^{\prime}$-phase in X-750 via in situ TEM irradiation at different temperatures using heavy ion irradiation. Their results clearly reveal that under irradiation at lower temperatures, the ordered precipitates become disordered at very low doses $(\sim 0.06 \mathrm{dpa})$, and also start to dissolve into the matrix at higher doses $(\sim 5 \mathrm{dpa})$. However, above a critical temperature which was between 400 and $500{ }^{\circ} \mathrm{C}$ at the dose rate used, the $\gamma^{\prime}$-precipitate remains stable and ordered. Similarly, Nelson et al. ${ }^{[13]}$ systematically studied the stability of $\gamma^{\prime}$-phase in Nimonic PE16 alloy and they found that the precipitate disordering occurred after room-temperature irradiation up to $0.1 \mathrm{dpa}$; however, the $\gamma^{\prime}$-phase remained ordered under irradiation at a temperature of $300{ }^{\circ} \mathrm{C}$. The instability of the ordered phase during irradiation is basically attributed to cascade-induced ballistic mixing, but at higher irradiation temperature, a thermally activated reordering process occurs simultaneously and prevents phase instability. ${ }^{[14]}$ The stability of $\gamma^{\prime}$-precipitates in this material is of great concern in nuclear applications, because its presence significantly impacts the strength, the ductility, and the hardness of the material. In this regard, it has been reported that disordered $\mathrm{Ni}_{3} \mathrm{Al}$ thin films exhibit nearly twice the strain to fracture, more than three times the fracture toughness, and about 20 pct lower hardness compared to the ordered $\mathrm{L1}_{2}$ state ${ }^{[15]}$ The influence of the irradiation-induced instability of $\gamma^{\prime}$-precipitate in Inconel X-750 on mechanical properties was investigated systematically during our previous study in which the hardness of room-temperature-irradiated X-750 was evaluated using the nano-indentation technique. ${ }^{[16]}$ Softening indentation behavior was detected that was more pronounced at higher irradiation doses. Indeed, it was found that the $\gamma^{\prime}$-disordering softening effect outweighed the hardening impact of irradiation-induced defects, and also $\gamma^{\prime}$ dissolution at higher doses causes more strength reduction to X-750 alloy.

It is well known that absorption of thermal neutrons by reactor components containing nickel leads to the enhanced production of displaced atoms, as well as the formation of hydrogen and helium. ${ }^{[8]}$ In particular, the $(n, \alpha)$ transmutation reaction, ${ }^{59} \mathrm{Ni}+n \rightarrow{ }^{56} \mathrm{Fe}+{ }^{4} \mathrm{He}$, is the result of the high neutron capture cross-section of ${ }^{59} \mathrm{Ni}$ over a wide range of neutron energies, leading to a high production rate of helium atoms (about $300 \mathrm{appm} / \mathrm{dpa}$ ) in X-750 during service in the CANDU reactor. ${ }^{[7]}$ The helium generation is always considered as a serious issue since it can degrade the mechanical properties, significantly. The most important impact of helium production is the stabilizing of irradiation-induced vacancies and vacancy clusters with the resultant generation of a high density of cavities in the microstructure. ${ }^{[17]}$ The effect of irradiation-induced cavities on mechanical properties of the X-750 alloy has not yet been investigated. However, Knapp et al. ${ }^{[18]}$ showed that implantation of 1 to 10 at. pct helium into pure $\mathrm{Ni}$ results in a fine dispersion of helium bubbles or cavities which are strong barriers to dislocation glide, and substantially strengthen the material. They also reported that the hardening effect of cavities depends on helium concentration, cavity size, and cavity density. In support of this, molecular dynamics (MD) simulations of dislocation-void interactions in pure Ni showed that the dislocation detachment angle decreases with increasing void size, which corresponds with an increase of the obstacle strength based on the line tension model. ${ }^{[19]}$ The obstacle strength increasing with void size is attributed to the increasing contact length between the dislocation and the void associated with the local annihilation and re-nucleation of a larger dislocation segment for a larger void. In addition to cavity generation, helium production has a significant effect on the stability of $\gamma^{\prime}$-precipitate as well as density and size of the other irradiation-induced defects. Our previous study on microstructural evolution in the X-750 alloy during dual-beam $(\mathrm{He} / \mathrm{Ni})$ irradiation clearly reveals that implanted helium atoms increase the stability of the $\gamma^{\prime}$-phase with the result that disordering occurs at much higher irradiation doses compared to single heavy ion irradiation. ${ }^{[9,20]}$ Furthermore, the size and density of interstitial-type defects such as the Frank loops increase with helium implantation, which is attributed to the hindering of vacancies and interstitial recombination by means of the consumption of irradiation-induced vacancies during cavity production and growth, with the consequent increase in the survival probabilities of free interstitials. ${ }^{[21]}$ Therefore, helium may have a significant impact on post-irradiation mechanical properties by not only promoting cavity generation, but also by changing the precipitate stability and distribution of defects.

As discussed above, there are several factors with different impacts which can alter the deformation behavior and the mechanical properties of the irradiated X-750 superalloy. These include $\gamma^{\prime}$-precipitate stability, helium production, and irradiation-induced defect formation. Until now, there have been just a few studies that explore the mechanical response of the irradiated X-750 alloy when a combination of the microstructural changes happen simultaneously. In fact, to gain a good understanding of mechanical property degradation mechanisms during service, it is crucial to study the combined effect of irradiation-induced microstructure evolution on the deformation behavior of the X-750 alloy. For this purpose, $\mathrm{Ni}^{+}$ion irradiation was carried out under different conditions, including with and without helium pre-implantation as well as at different irradiation temperatures. Then, the nano-indentation technique was employed to evaluate the nano-hardness of irradiated material. Also, cross-sectional TEM observations were performed on the irradiated material to correlate the microstructure and observed mechanical properties. Finally, three different obstacle-hardening models were used to distinguish the contribution of each type of defect to the post-irradiation mechanical behavior. 


\section{EXPERIMENTAL PROCEDURE}

The chemical composition of the studied X-750 material is presented in Table I. Before irradiation, solution annealing was carried out at $1150{ }^{\circ} \mathrm{C}$ for 1 hour followed for 60 pct rolling and recrystallization annealing at $960{ }^{\circ} \mathrm{C}$ for 10 minutes. The final heat treatment stage was an age hardening procedure performed at $730{ }^{\circ} \mathrm{C}$ for 16 hours. The microstructure of the $\mathrm{X}-750$ alloy after aging is shown in Figure 1, indicating spherical $\gamma^{\prime}$-precipitates with the size of 20 to $25 \mathrm{~nm}$. Four samples were prepared with dimension of 1 $\mathrm{cm} \times 1 \mathrm{~cm} \times 1 \mathrm{~mm}$ thickness for irradiation and indentation experiments.

Different irradiation procedures including single selfion irradiation and helium pre-implantation followed by self-ion irradiation were employed. Single self-ion irradiation was conducted by using $40 \mathrm{MeV} \mathrm{Ni}^{+}$ions at $400{ }^{\circ} \mathrm{C}$ up to a nominal damage level of $1 \mathrm{dpa}$. Seven different energies from $200 \mathrm{keV}$ to $3 \mathrm{MeV}$ (starting with higher energy) were used at $300{ }^{\circ} \mathrm{C}$ to implant $5000 \mathrm{appm}$ helium into other samples. These preimplanted samples were subsequently irradiated by $\mathrm{Ni}^{+}$ions up to $1 \mathrm{dpa}$ at $400{ }^{\circ} \mathrm{C}$ and room temperature. In order to control and monitor the experiment temperature, a thermocouple was attached just behind the irradiation location. The error on the temperature reading was $\approx 10^{\circ} \mathrm{C}$. The summary of irradiation procedures along with samples' names is tabulated in Table II. The $\mathrm{Ni}^{+}$ion irradiation damage and implanted helium concentration calculations were conducted based on SRIM code 2012 using the KinchinPease approximation (Counting about 30,000 ions until reaching to a steady state in the predictions). ${ }^{[22]}$ Figure 2(a) depicts the helium concentration curves as a function of sample depth for different helium beam energies and Figure 2(b) presents the damage level of $\mathrm{Ni}^{+}$ions $v s$ target depth by assuming threshold displacement energy of $40 \mathrm{eV}$. Different helium beam energies were chosen to obtain a more homogenous implanted helium distribution while also obtaining a maximum implanted depth of around $5 \mu \mathrm{m}$, equal to the $\mathrm{Ni}^{+}$ion irradiation stopping peak depth.

It should be noted that the level of displacement damage caused by helium implantation (average 0.015 dpa) is negligible compared to the $\mathrm{Ni}^{+}$ion irradiation damage level. Nano-indentation hardness experiments were performed on both un-irradiated and irradiated material using a Nano Test Vantage device equipped with a Berkovich indenter. In order to obtain the hardness profile as a function of sample depth, the quasi-static method in a depth control mode with loading and unloading rate of $2 \mathrm{mN} / \mathrm{s}$ was employed at room temperature and at least ten indents on each depth were carried out to get good statistical data. It should be noted that indentations were performed on the irradiated surface in the same direction as the ion beam irradiation. The area function for hardness measurements was estimated by means of indentation on a fused silica standard sample. Cross-sectional TEM foils were fabricated by means of focused ion beam (FIB) from irradiated samples. The ion beam used was $\mathrm{Ga}^{+}$with starting and finishing energy of 30 and $5 \mathrm{kV}$, respectively. Microstructural examinations were carried out using FEI Tecnai Osiris scanning transmission electron microscope (STEM) at an operating voltage of $200 \mathrm{kV}$. Underfocus Fresnel contrast under twobeam kinematical bright-field condition was adopted to observe the small cavities. In addition, characterization of the Frank loops was conducted by employing the TEM rel-rod condition.

\section{RESULTS}

\section{A. Nano-indentation Behavior}

\section{Hardness profile}

The measured nano-hardness profiles as a function of indentation depth are presented in Figure 3. The effect of helium pre-implantation on indentation behavior of X-750 alloy is clear in Figure 3(a). The results show irradiation-induced hardening for both $\mathrm{He}-\mathrm{Ni}$ at $400{ }^{\circ} \mathrm{C}$ and $\mathrm{Ni}$ at $400{ }^{\circ} \mathrm{C}$; however, the level of hardness enhancement is more in the helium pre-implanted sample compared to single $\mathrm{Ni}$ ion-irradiated sample. Indeed, helium pre-implantation increased the hardening effect of $\mathrm{Ni}^{+}$ion irradiation during the deformation of X-750 alloy. Furthermore, the influence of subsequent self-ion irradiation temperature on nano-hardness of X-750 alloy is presented in Figure 3(b). The hardness profiles depict that $\mathrm{He}$ implantation and subsequent self-ion irradiation at $400{ }^{\circ} \mathrm{C}$ made the material harder than the un-irradiated material. In contrast, changing the $\mathrm{Ni}^{+}$ion irradiation temperature to room temperature $\left(26^{\circ} \mathrm{C}\right)$ resulted in a softening behavior of the material.

\section{Indentation size effect}

As is illustrated in Figure 3, the decreasing measured hardness with increasing indentation depth can be found in the hardness profile of all conditions other than the $\mathrm{He}-\mathrm{Ni}$ at RT sample. This is called the indentation size effect (ISE), which is well explained by Nix and Gao ${ }^{[23]}$ based on the concept of geometrically necessary dislocations (GNDs), that is, dislocations that must be present to accommodate the imposed strain by the indenter at the surface. To quantify the ISE in the irradiated and un-irradiated X-750, the Nix-Gao (NG)

Table I. Chemical Composition of the Inconel X-750 (Weight Percent)

\begin{tabular}{llllllll}
\hline $\mathrm{Ni}$ & $\mathrm{Cr}$ & $\mathrm{Fe}$ & $\mathrm{Ti}$ & $\mathrm{Al}$ & $\mathrm{Nb}$ & $\mathrm{Mn}$ & $\mathrm{C}$ \\
\hline Bal. & 15 & 7.3 & 2.5 & 0.68 & 0.99 & 0.15 & 0.067 \\
\hline
\end{tabular}



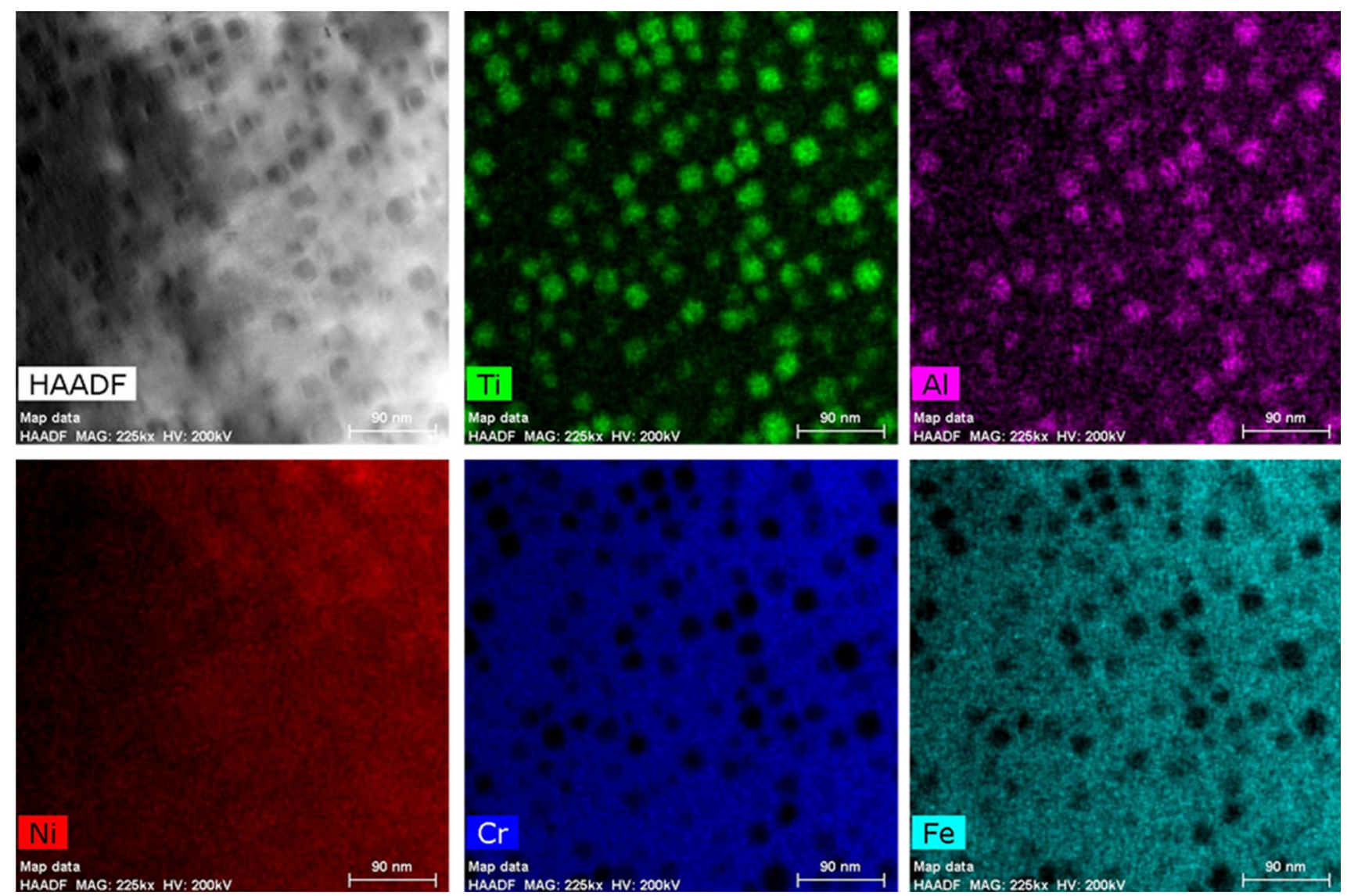

Fig. 1-The EDX-chemical map of X-750 alloy, showing $\gamma^{\prime}$-precipitate distribution before irradiation.

Table II. Summary of Irradiation Conditions Applied for Each Sample

\begin{tabular}{ll}
\hline Sample's Name & \multicolumn{1}{c}{ Irradiation Condition } \\
\hline He-Ni at $400{ }^{\circ} \mathrm{C}$ & 5000 appm He implanted at \\
& $300{ }^{\circ} \mathrm{C}$-subsequent $1 \mathrm{dpa}$ \\
& $\mathrm{Ni}^{+}$at $400{ }^{\circ} \mathrm{C}$ \\
$\mathrm{He}-\mathrm{Ni}$ at RT & 5000 appm He implanted at \\
& $300{ }^{\circ} \mathrm{C}$ - subsequent \\
& $1 \mathrm{dpa} \mathrm{Ni}^{+}$at RT \\
$\mathrm{Ni}$ at $400{ }^{\circ} \mathrm{C}$ & $1 \mathrm{dpa} \mathrm{Ni}{ }^{+}$at $400{ }^{\circ} \mathrm{C}$ \\
\hline
\end{tabular}

model was employed which shows the relation between the hardness and indentation depth according to Eq. [1].

$$
H=H_{0}\left(1+\frac{h^{*}}{h}\right)^{1 / 2}
$$

where $H$ is the indentation hardness at the depth of the $h, H_{0}$ is the macroscopic hardness, i.e., the hardness at a very large depth, and $h^{*}$ is the characteristic depth, which characterizes the depth-dependence of hardness. The results are presented as the curve of $H^{2} v s 1 / h$ for both un-irradiated and irradiated samples in Figure 4. Two different ISE trends were obtained, including bi-linear behavior, i.e., two different slopes for nanoand micro-indentation, for un-irradiated material, as well as a very strongly linear trend for irradiated X-750 (He-Ni at $400{ }^{\circ} \mathrm{C}$ sample).
In the case of the bi-linear ISE behavior, a good linear relation was found based on the NG model for an indentation depth bigger than $600 \mathrm{~nm}$; however, the NG model overestimates the hardness at smaller indents which was observed as a deviation from the micro-indentation in Figure 4(a). Therefore, the ISE curve was divided into two different regimes (nano and micro-indentation) and separate NG constants $\left(H_{0}\right.$ and $\left.h^{*}\right)$ were calculated related to each regime; this terminology of 'nano' and 'micro' refers only to the length scale of indentation behavior, the same indentor is used in all cases. The results are presented in Table III. Considering the micro-regime of ISE curves, $h^{*}$ reduction after irradiation implies a lower size effect in irradiated material vs un-irradiated X-750, which is in agreement with the observations of previous authors in other FCC materials. ${ }^{[24]}$

\section{B. Cross-Sectional TEM Observations}

\section{Cavity development}

Figures 5 and 6 illustrate the underfocus kinematical bright-field TEM micrographs of samples with 5000 appm helium which were irradiated at $400{ }^{\circ} \mathrm{C}$ and room temperature, respectively. The cavity development has been shown at seven locations, which correspond to the stopping peak locations of the applied seven energies used for helium implantation (See Figure 2). Figure 5 depicts the high density of 


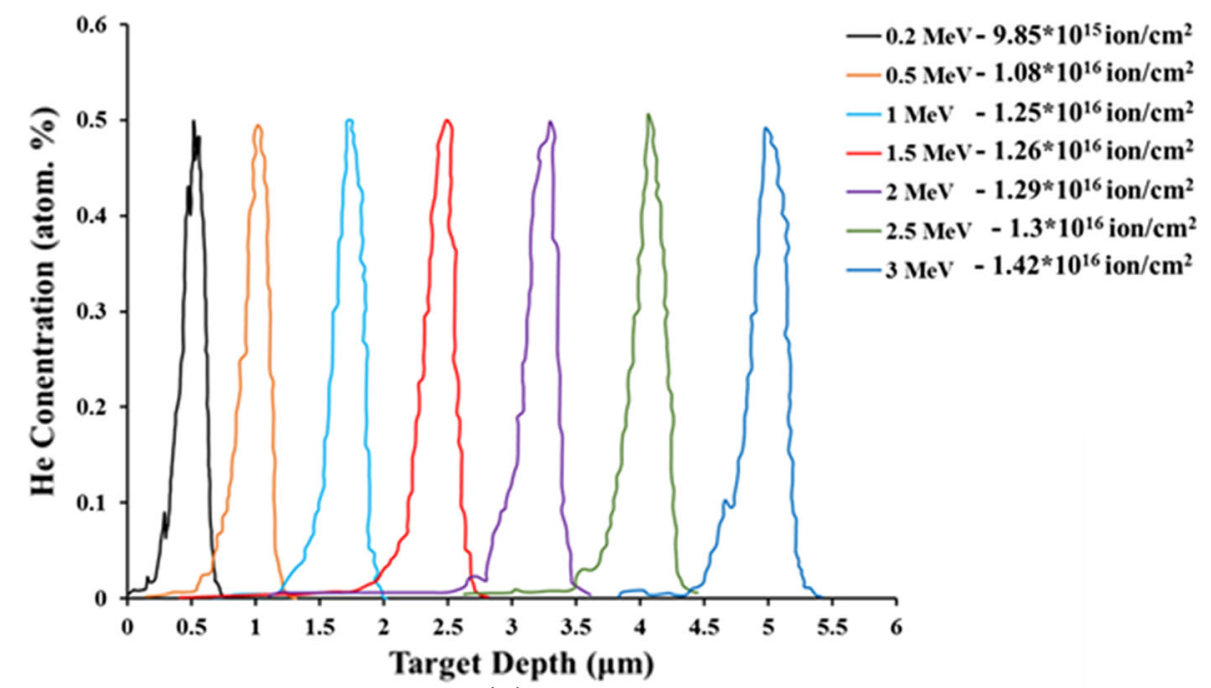

(a)

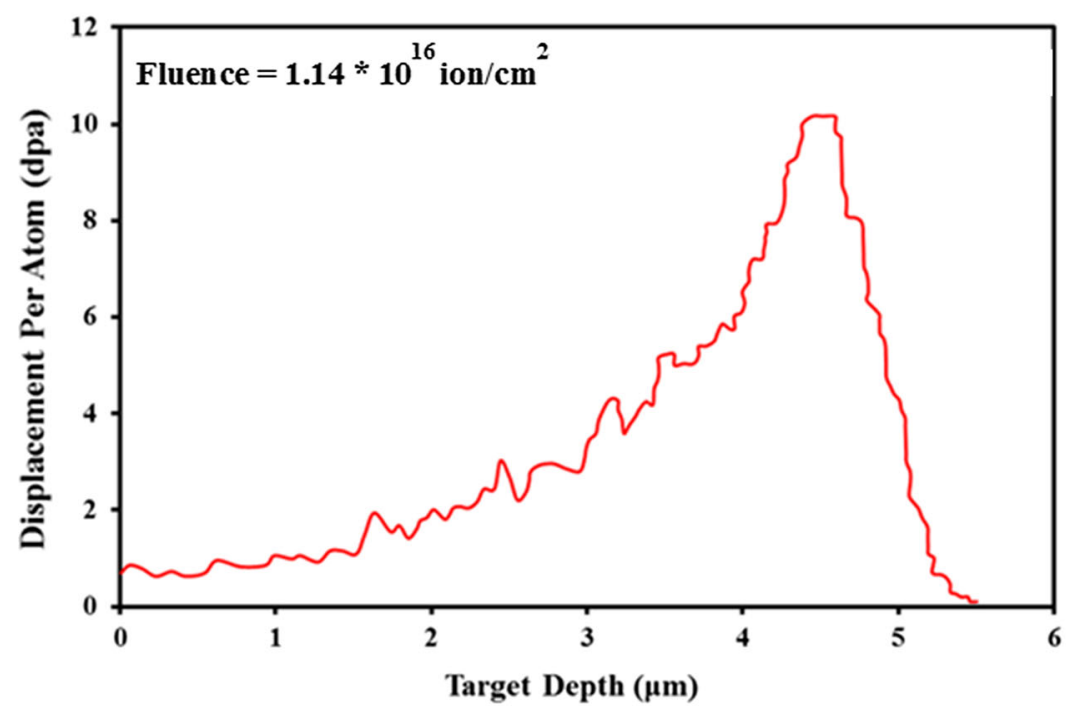

(b)

Fig. 2-SRIM simulation for (a) helium pre-implantation, showing helium concentration as a function of target depth $(b) \mathrm{Ni}^{+}$ion irradiation, depicting displacement damage dose variation $v$ s target depth.

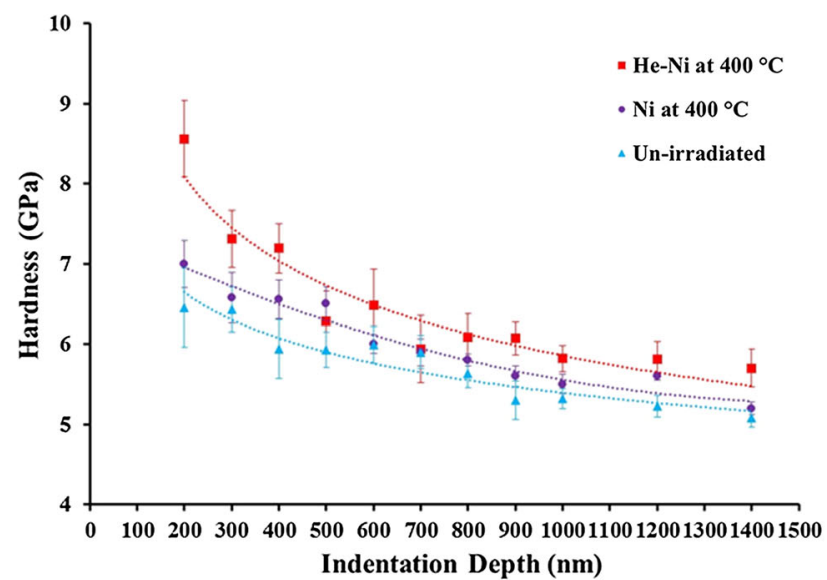

(a)

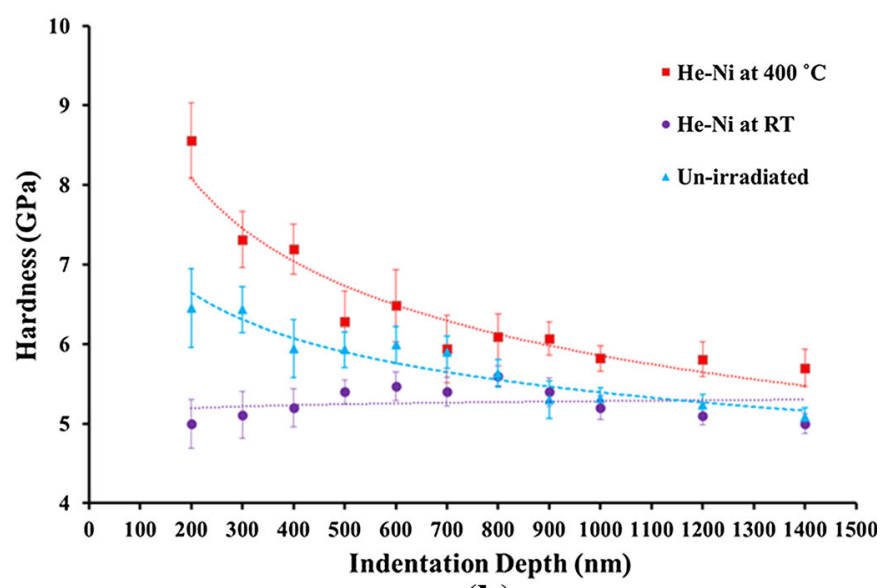

(b)

Fig. 3-Nano-hardness variations as a function of indentation depth, showing the effect of $(a)$ helium pre-implantation and $(b) \mathrm{Ni}+$ ion irradiation temperature. 
homogenously distributed small cavities with an average size of about $1.2 \pm 0.2 \mathrm{~nm}$ for all seven stopping peak locations. It should be mentioned that the much lower amount of implanted helium at locations between the peak areas caused significant reduction of cavity density, as is presented in Figure 7.

In the sample irradiated at room temperature, the cavity density is lower than the sample irradiated at $400{ }^{\circ} \mathrm{C}$, and the cavities' average size is bigger $(2 \pm 0.2$ $\mathrm{nm})$. The cavity size distribution diagrams in both helium pre-implanted samples are depicted in Figure 8. The cavity size distribution for irradiated material at $400{ }^{\circ} \mathrm{C}$ follows a normal distribution; however, after irradiation at room temperature, a wide range of sizes from $<0.5$ to $5 \mathrm{~nm}$ was measured. In the single $\mathrm{Ni}$ ion-irradiated sample $\left(\mathrm{Ni}\right.$ at $\left.400{ }^{\circ} \mathrm{C}\right)$, no cavities were detected (Figure 9), which is consistent with previous results on microstructural observation of X-750 after single ion irradiation without He pre-implantation. ${ }^{[9]}$ It is worth mentioning that the cavity size measurements have been performed for each stopping peak location separately and the size distribution curve was plotted using the sum of all of that data. In case of He-Ni at $400{ }^{\circ} \mathrm{C}$, the cavity size was about the same diameter at all seven locations. However, in He-Ni at RT, a bigger cavity size was detected at locations corresponding to the higher energies. The cavity size distribution was shown in both samples at all stopping peak area locations.

The common method for estimation of cavity density is to directly count the number of cavities inside of a particular sample volume. The very small cavity size, possible overlapping, and sparse distributions, make the procedure challenging for density calculation. Therefore, we used the pressure-based method adopted by Knapp et al. ${ }^{[18]}$ to estimate the cavity density:

$$
p=\frac{2 \gamma+\mu b}{r},
$$

where $p$ is the cavity pressure, $\gamma=2.28 \mathrm{j} / \mathrm{m}^{2}$ is the surface energy for $\mathrm{Ni}{ }^{[18]}, r$ is the cavity radius, $\mu=77.8$ $\mathrm{GPa}$ is the shear modulus of $\mathrm{Ni}$, and $b=0.247 \mathrm{~nm}$ is the magnitude of Burgers vector of Ni. Then, the atomic density of helium $\left(\rho_{\mathrm{He}}\right)$ at the pressure of $p$ was calculated by using the Equation-of-Sate of helium. ${ }^{[25,26]}$

$$
\begin{aligned}
\rho_{\mathrm{He}}= & \left(22.575+0.0064655 T-7.2645 T^{-0.5}\right) P^{-\frac{1}{3}} \\
& +(-12.483-0.024549 T) P^{-\frac{2}{3}} \\
& +\left(1.0596+0.10604 T-19.641 T^{-\frac{1}{2}}+189.84 T^{-1}\right) P^{-1},
\end{aligned}
$$

where $T=300{ }^{\circ} \mathrm{C}$ is the helium implantation temperature.

Assuming that all the helium atoms reside within the cavities, ${ }^{[27]}$ the number of helium atoms in a single cavity can be estimated by

$$
N_{\mathrm{He}}=\frac{V_{\text {cavity }}}{\rho_{\mathrm{He}}}=\frac{\frac{4}{3} \pi r^{3}}{\rho_{\mathrm{He}}} .
$$

Finally, the cavity density can be computed according to Eq. [5].

$$
d_{\text {cavity }}=R_{\mathrm{He}} \times \frac{\rho_{\mathrm{Ni}}}{N_{\mathrm{He}}},
$$

where the $d_{\text {cavity }}$ is the cavity density, $R_{\mathrm{He}}$ is the atomic concentration of implanted helium in the sample $(0.25$ at. pct), and the $\rho_{\mathrm{Ni}}$ is the $\mathrm{Ni}$ atomic density. The corresponding values of the cavity density in both samples of $\mathrm{He}-\mathrm{Ni}$ at $400{ }^{\circ} \mathrm{C}$ and $\mathrm{He}-\mathrm{Ni}$ at $\mathrm{RT}$ are tabulated in Table IV. For comparison, the cavity density was also estimated using TEM micrographs, resulting in $2.5 \times 10^{23}$ and $2.1 \times 10^{23} \mathrm{~m}^{-3}$ for He-Ni at $400{ }^{\circ} \mathrm{C}$ and $\mathrm{He}-\mathrm{Ni}$ at $\mathrm{RT}$ sample, respectively. The cavity density obtained based on the Knapp method is about 5 and 1.6 times higher than that found with TEM measurements for $\mathrm{He}-\mathrm{Ni}$ at $400{ }^{\circ} \mathrm{C}$ and $\mathrm{He}-\mathrm{Ni}$ at $\mathrm{RT}$ sample, respectively. The smaller size of cavities in $\mathrm{He}-\mathrm{Ni}$ at $400{ }^{\circ} \mathrm{C}$ makes the counting of cavities and density measurements more challenging; we believe that is the reason that the difference is more pronounced for this sample compared to the He-Ni at RT sample.

Cavity morphology and distribution were observed close to grain boundaries in helium-implanted samples (Figure 10). It is clear that the grain boundaries are perforated by an array of cavities in both conditions, which is very similar to what was found in the microstructure of an ex-service CANDU reactor X-750 annulus spacer. ${ }^{[6]}$ Also, in the $\mathrm{He}-\mathrm{Ni}$ at $400{ }^{\circ} \mathrm{C}$ sample, an area close to the grain boundary was found to contain no cavities, which represents a denuded cavity zone (Figure 10(a)).

The width of the denuded zone (about $12 \mathrm{~nm}$ ) is smaller than what was found in neutron-irradiated material (about $30 \mathrm{~nm}$ ). In contrast, the $\mathrm{He}-\mathrm{Ni} \mathrm{RT}$ sample did not show a denuded zone. In addition, grain boundary cavities in the He-Ni RT sample show a larger size compared to cavities in the matrix, while in the $\mathrm{He}-\mathrm{Ni}$ at $400{ }^{\circ} \mathrm{C}$ sample, the grain boundary cavities are approximately the same size as the matrix cavities.

\section{2. $\gamma^{\prime}$-precipitate stability}

TEM characterization was carried out to explore the $\gamma^{\prime}$-precipitate stability after irradiation. The $\gamma^{\prime}$ phase has a FCC-ordered $\mathrm{L}_{2}$ structure, which causes superlattice reflections in the TEM diffraction pattern. Therefore, the diffraction patterns on the (110) pole at different depths were captured to find any $\gamma^{\prime}$-instability as a function of irradiation depth and the results are presented in Figure 11. As is shown in Figure 11(a) and (b), $\gamma^{\prime}$ superlattice reflections were found at different locations in the irradiated region as well as the un-irradiated layer in the $\mathrm{He}-\mathrm{Ni}$ at $400{ }^{\circ} \mathrm{C}$ and $\mathrm{Ni}$ at $400{ }^{\circ} \mathrm{C}$ samples. In contrast, in the He-Ni at RT sample (Figure 11(c)), superlattice reflections disappeared in the irradiated region.

Therefore, the $\gamma^{\prime}$ phase stayed ordered after helium implantation and subsequent $\mathrm{Ni}$ irradiation at $400{ }^{\circ} \mathrm{C}$ as well as single $\mathrm{Ni}$ ion irradiation at $400{ }^{\circ} \mathrm{C}$; however, disordering of $\gamma^{\prime}$ happened under the condition of $\mathrm{He}-\mathrm{Ni}$ at RT. While it is worth mentioning that although the 


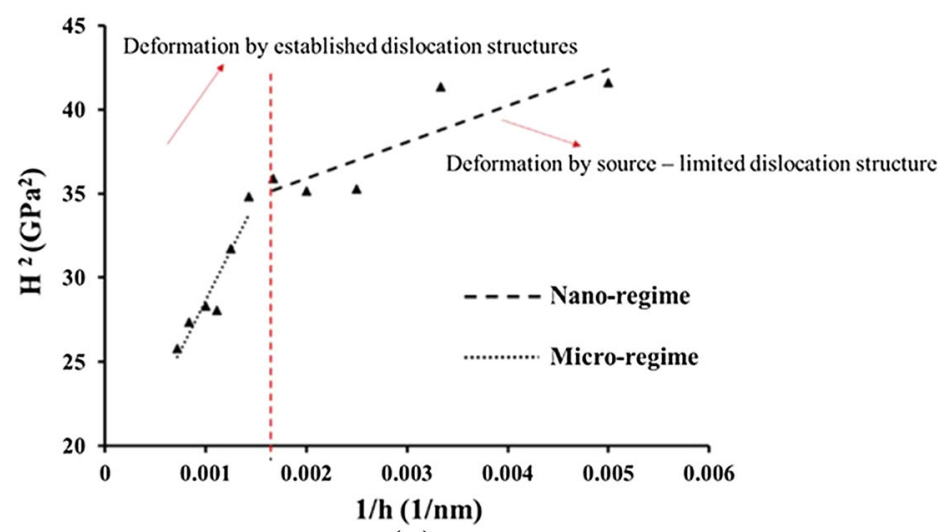

(a)

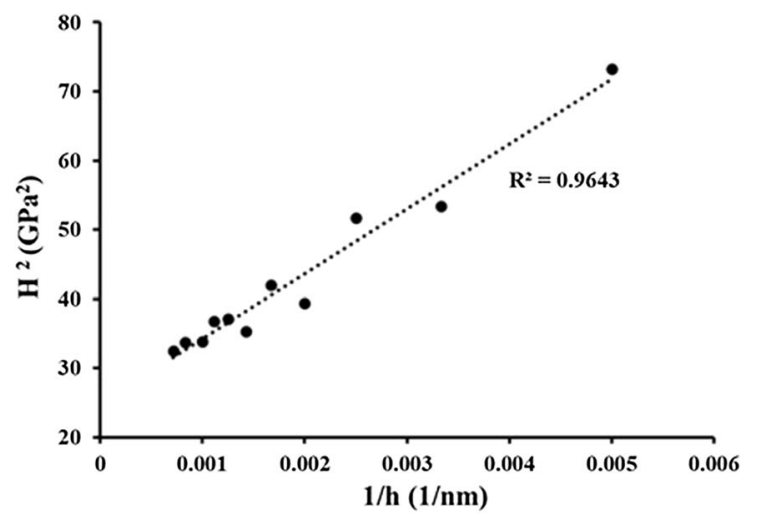

(b)

Fig. $4-\mathrm{H}^{2}$ vs $1 / h$ curve for $(a)$ un-irradiated $\mathrm{X}-750$ and $(b) \mathrm{He}-\mathrm{Ni}$ at $400{ }^{\circ} \mathrm{C}$ irradiated $\mathrm{X}-750$, showing indentation size effect behavior.

Table III. ISE Constants for Un-irradiated, Ni at $400{ }^{\circ} \mathrm{C}$ and $\mathrm{He}-\mathrm{Ni}$ at $400{ }^{\circ} \mathrm{C}$ Samples Based on Nix-Gao Model

\begin{tabular}{|c|c|c|c|c|}
\hline Sample & \multicolumn{2}{|c|}{$H_{0}(\mathrm{GPa})$} & \multicolumn{2}{|c|}{$h^{*}(\mathrm{~nm})$} \\
\hline Un-irradiated & $\begin{array}{l}\text { nano-regime } \\
\text { micro-regime }\end{array}$ & $\begin{array}{l}5.54 \\
4.16\end{array}$ & $\begin{array}{l}\text { nano-regime } \\
\text { micro-regime }\end{array}$ & $\begin{array}{l}76 \\
650\end{array}$ \\
\hline $\mathrm{He}-\mathrm{Ni}$ at $400{ }^{\circ} \mathrm{C}$ & & 4.98 & & 377 \\
\hline
\end{tabular}
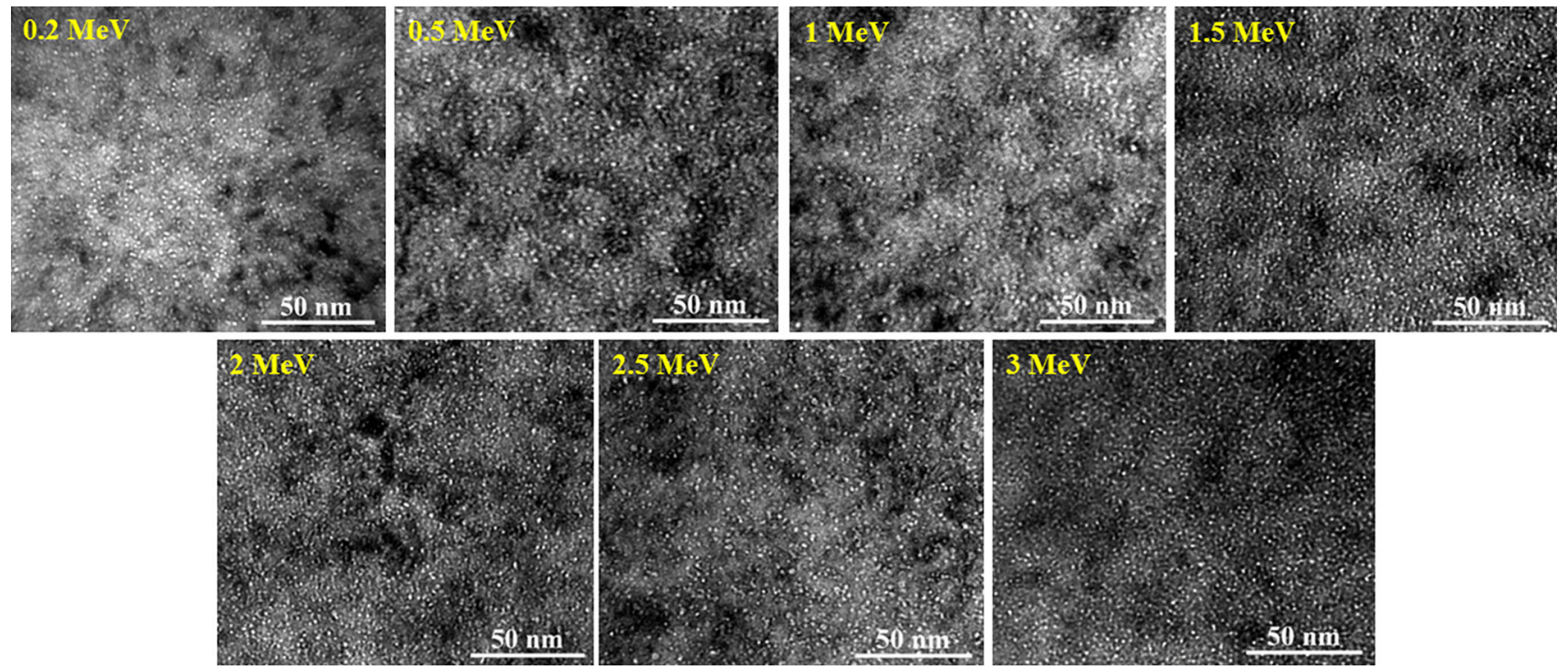

Fig. 5- Cavity distribution at the stopping peak areas of helium beams with different energies in the He-Ni at $400{ }^{\circ} \mathrm{C}$ irradiated $\mathrm{X}-750$.

concentration of implanted helium was much lower in areas between the stopping peak locations, no changes in superlattice reflection were found at different depths of the samples.

\section{Irradiation-induced Frank loops}

The rel-rod condition was adapted to characterize the $1 / 3<111>$ Frank loops. The Frank loops were detected in all the irradiation conditions, which are presented in Figure 12 in two different magnifications along with the dislocation loop size distribution. However, the size and the density of the loops are changed by the implantation of helium, or by changing the $\mathrm{Ni}$ ion irradiation temperature. The size and density calculations are shown in Table IV. The results show that a larger size and a higher density of Frank loops were obtained for the helium pre-implanted sample irradiated at $400{ }^{\circ} \mathrm{C}$, compared to the sample irradiated at the same temperature by single $\mathrm{Ni}^{+}$ions. Also, increasing the self-ion irradiation temperature led to an increase in the size and the density of the Frank loops. As noted above, in order to estimate the density of the Frank loops, the thickness of the samples was measured using the EELS (electron energy loss spectroscopy) method. To understand the 

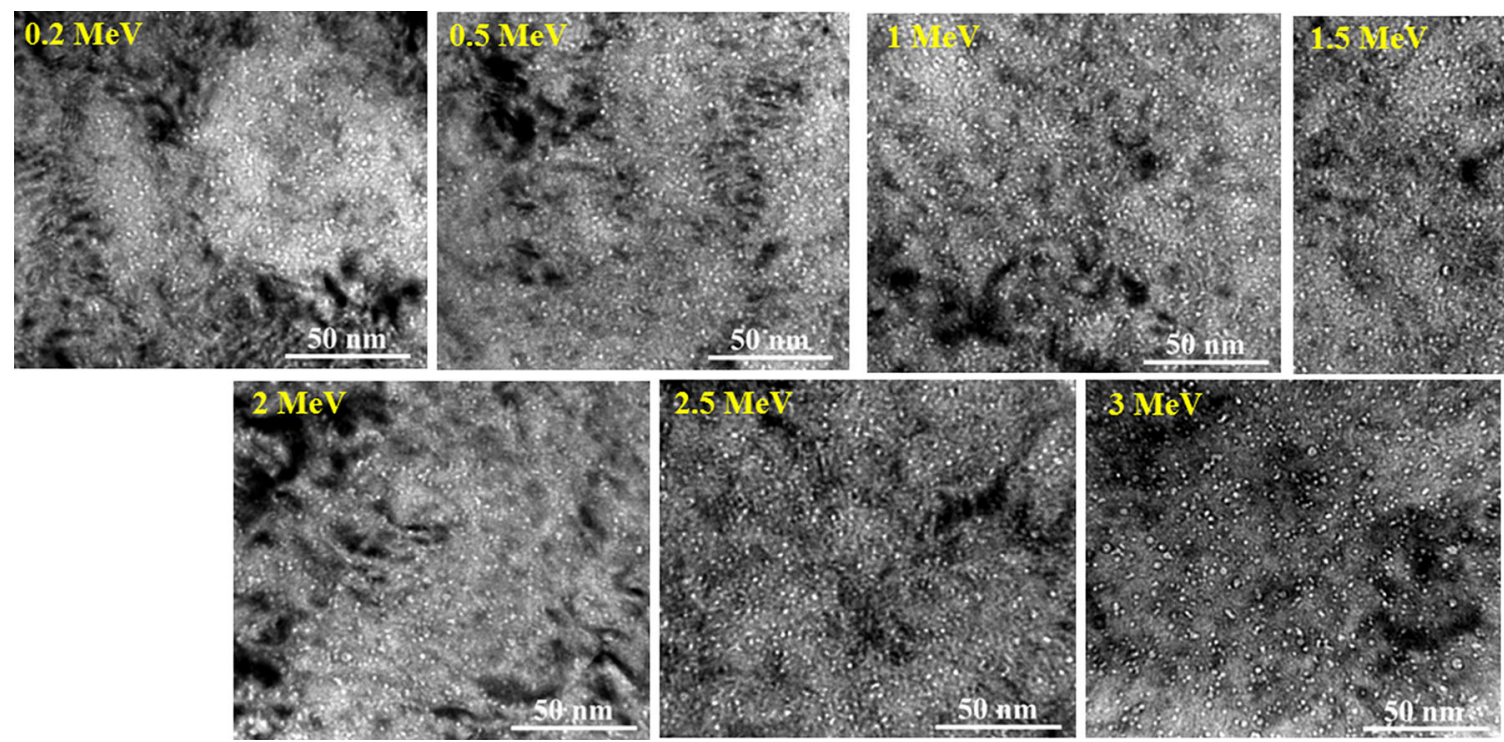

Fig. 6-Cavity distribution at the stopping peak areas of helium beams with different energies in the He-Ni at RT-irradiated X-750.
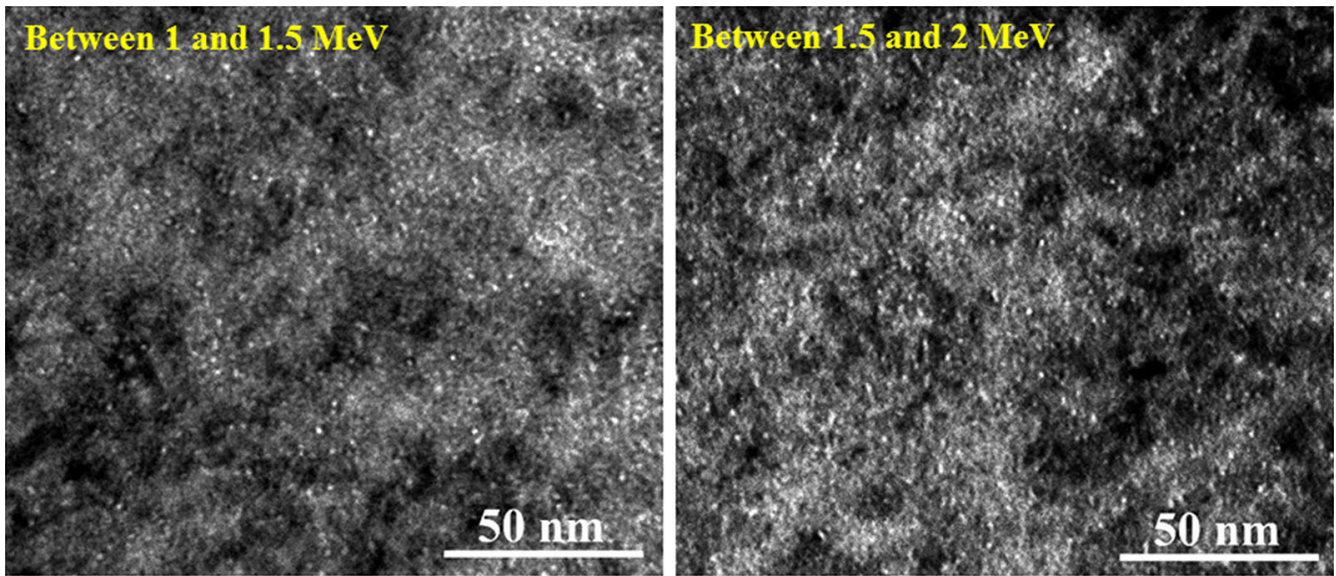

Fig. 7-Cavity distribution at the areas between the stopping peak zones in the $\mathrm{He}-\mathrm{Ni}$ at $400{ }^{\circ} \mathrm{C}$ irradiated $\mathrm{X}-750$.

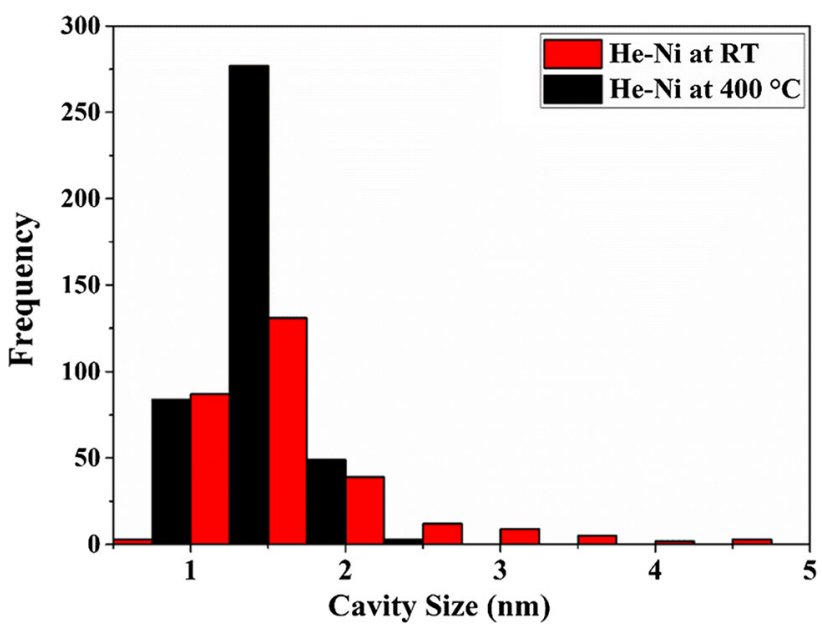

Fig. 8- Cavity size distribution in $\mathrm{He}-\mathrm{Ni}$ at $400{ }^{\circ} \mathrm{C}$ and $\mathrm{He}-\mathrm{Ni}$ at RT-irradiated X-750.

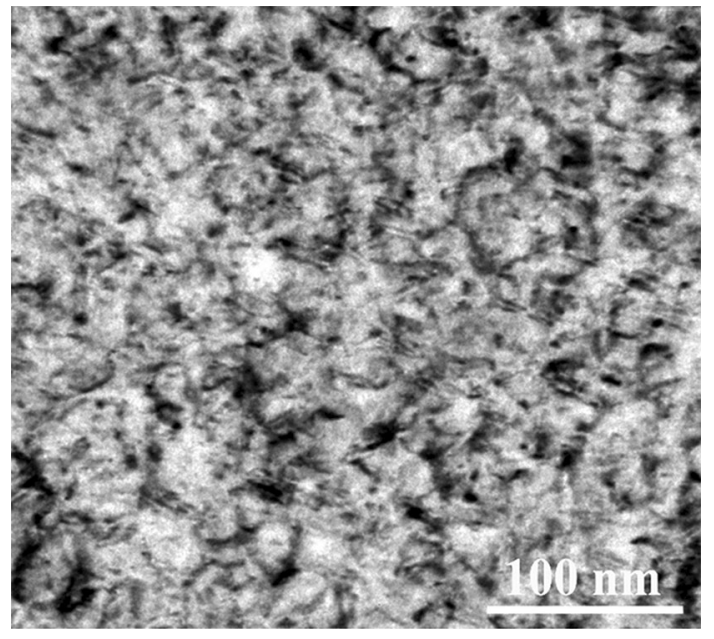

Fig. 9-Underfocus bright-field TEM micrograph from single $\mathrm{Ni}$ ion-irradiated material. 
Table IV. The Results of Cavity and Frank Loop Size and Density Measurements

\begin{tabular}{|c|c|c|c|c|c|}
\hline Sample & $\begin{array}{c}\text { Cavity } \\
\text { Size (nm) }\end{array}$ & $\begin{array}{c}\text { Cavity } \\
\text { Density }\left(\mathrm{m}^{-3}\right)\end{array}$ & $\begin{array}{c}\text { Cavity } \\
\text { Spacing }(\mathrm{nm})\end{array}$ & $\begin{array}{l}\text { Frank Loop } \\
\text { Size }(\mathrm{nm})\end{array}$ & $\begin{array}{l}\text { Frank Loop } \\
\text { Density }\left(\mathrm{m}^{-3}\right)\end{array}$ \\
\hline $\mathrm{He}-\mathrm{Ni}$ at $400^{\circ} \mathrm{C}$ & $1.2 \pm 0.2$ & $1.34 \times 10^{24}$ & 25 & $20 \pm 2$ & $9.2 \times 10^{21}$ \\
\hline $\mathrm{He}-\mathrm{Ni}$ at $\mathrm{RT}$ & $2 \pm 0.2$ & $3.4 \times 10^{23}$ & 38 & $12 \pm 2$ & $7.2 \times 10^{21}$ \\
\hline $\mathrm{Ni}$ at $400^{\circ} \mathrm{C}$ & - & - & - & $13 \pm 2$ & $7.7 \times 10^{21}$ \\
\hline
\end{tabular}

effect of irradiation-induced microstructural changes on the mechanical behavior of X-750 Ni-based superalloy, it is essential to correlate the results of indentation hardness measurements to the cross-sectional TEM observations.

\section{DISCUSSION}

\section{A. Effect of Helium Pre-implantation}

In order to explore the effect of helium pre-injection on the mechanical behavior of $\mathrm{X}-750$, the results of an indentation experiment for single $\mathrm{Ni}$ ion irradiation at $400{ }^{\circ} \mathrm{C}$, and $\mathrm{He}-\mathrm{Ni}$ at $400{ }^{\circ} \mathrm{C}$ should be considered. Nano-scale mechanical tests revealed that prior helium implantation caused a greater hardness increment compared to $\mathrm{Ni}$ ion irradiation alone, at the same temperature. As was depicted in TEM examinations of He-Ni at $400{ }^{\circ} \mathrm{C}$, helium influences the post-irradiation microstructural changes which impact the subsequent mechanical response of the X-750 alloy.

Cavity generation as a result of mutual trapping of vacancies and helium atoms, is one of the important influences of helium implantation which was not detected in the single ion-irradiated sample. As was shown in Figure 5, the high density of cavities at the stopping peak areas of helium implantation causes significant hardening in $\mathrm{He}-\mathrm{Ni}$ at $400{ }^{\circ} \mathrm{C}$ sample during indentation, compared to the un-irradiated material. Reichardt et al. ${ }^{[28]}$ studied the in situ tensile deformation of helium implanted single crystal $\mathrm{Ni}$, and the results showed no slip traces in the helium stopping peak region, and it ruptured under extremely high stresses. This suggests that the cavities do not allow dislocations to move further on their slip systems; therefore, implying that cavities are strong obstacles to dislocation movement. In supporting this, a work by Knapp et al. ${ }^{[18]}$ on nano-indentation hardness measurement of helium injected pure $\mathrm{Ni}$, showed that even $1 \mathrm{~nm}$ cavities can hinder dislocations significantly and that the $\mathrm{Ni}$ can be strengthened to approximately seven times higher hardness than in the un-irradiated state. In order to show physical evidence of cavity-dislocation interaction, a bright-field underfocus TEM micrograph is presented in Figure 13. The individual gliding dislocations along with small cavities are depicted in the indentation plastic zone of $\mathrm{He}-\mathrm{Ni}$ at $400{ }^{\circ} \mathrm{C}$ sample. It is known that the cavity strengthening effect is dependent on helium concentration, cavity size, and cavity density. However, recent atomistic modeling has shown that the strength of cavities (with a constant size) on pinning of the dislocation glide is dependent on the helium-to-vacancy ratio in a cavity, or the cavity pressure. ${ }^{[19,29,30]}$ Indeed, the maximum effective shear stress of a cavity arises from internal pressure, and increases with increasing cavity pressure. ${ }^{[26]}$

It was also found that helium can affect the size and density of irradiation-induced Frank loops (Table IV). The bigger size and higher density of Frank loops in $\mathrm{He}-\mathrm{Ni}$ at $400{ }^{\circ} \mathrm{C}$ sample vs $\mathrm{Ni}$ at $400{ }^{\circ} \mathrm{C}$ specimen also promote hardness enhancement observed during indentation. The TEM characterization on ex-service neutron-irradiated X-750 alloy revealed that the Frank loops are basically interstitial-type defects. ${ }^{[5]}$ The presence of helium atoms can provide more free interstitials, by preferential trapping and hence absorption of vacancies with the eventual formation of cavities; hence, injection of helium may lead to the generation of a higher density of larger Frank (interstitial) loops. It is worthwhile to note, implantation of such a high amount of helium (5000 appm) before $\mathrm{Ni}$ ion irradiation, not only increased the size and density of interstitial defects like Frank loops, but also decreased the size and density of vacancy-type defects; i.e., stacking fault tetrahedras (SFTs). In supporting this, Zhang et al. ${ }^{[31]}$ reported that after pre-implantation of just 200 appm helium atoms, the SFT fraction reduces from 55 to 10 pct after ion irradiation of $\mathrm{X}-750$ at $400{ }^{\circ} \mathrm{C}$. Zinkle et al. ${ }^{[32]}$ proposed a model to elucidate the effect of helium on the stability of vacancy clusters in irradiated copper, and they suggested that even a very low amount of helium (0.001 appm) can stabilize vacancies, instead of allowing them to form SFTs at certain irradiation temperatures. Therefore, we can strongly anticipate that the SFT fraction in the helium implanted sample is dramatically lower; however, a significant fraction of defects (approximately $50 \mathrm{pct}$ ) in the single ion-irradiated sample are SFTs.

In summary, helium may affect the mechanical behavior of irradiated X-750 Ni-based superalloy through stabilizing the irradiation-induced vacancies and generating a high density of cavities-promoting formation of big interstitial defects such as Frank loops.

\section{B. Effect of Subsequent Self-Ion Irradiation Temperature}

Mechanical property tests also showed that irradiation temperature has a significant effect on the mechanical behavior of X-750 (Figure 3(b)). The reason for the hardness reduction in $\mathrm{He}-\mathrm{Ni}$ at $\mathrm{RT}$ sample vs hardness enhancement in the $\mathrm{He}-\mathrm{Ni}$ at $400{ }^{\circ} \mathrm{C}$ sample should be traced to the post-irradiation microstructure. The main difference found in the cross-sectional observations is the $\gamma^{\prime}$-precipitate state, which becomes disordered in the 

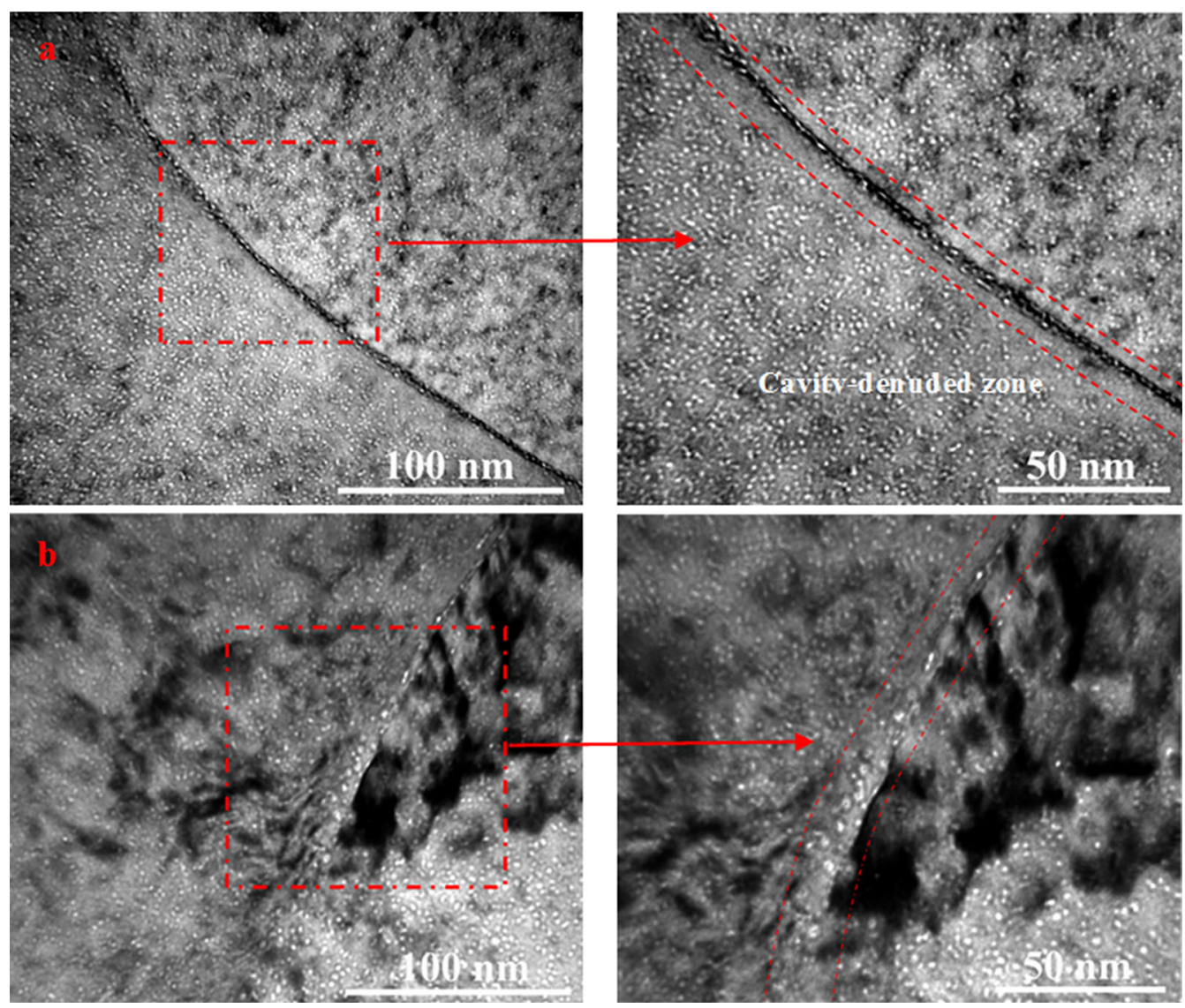

Fig. 10 - Cavity distribution close to grain boundaries in (a) He-Ni at $400{ }^{\circ} \mathrm{C}$ and (b) $\mathrm{He}-\mathrm{Ni}$ at RT samples.

room-temperature-irradiated sample, while remaining ordered in the higher temperature irradiation condition. (Figure 11). Although, the He-Ni at RT sample contains a high concentration of $5000 \mathrm{appm}$ helium (which may postpone the $\gamma^{\prime}$-phase disordering, ${ }^{[20]}$ ), a low irradiation temperature at which the $\gamma^{\prime}$ rate of thermal recovery process is very slow which leads to precipitate disordering. Indeed, ballistic mixing results from collision cascade of $\mathrm{Ni}^{+}$ions is predominant at low temperatures; however, increasing the temperature to $400{ }^{\circ} \mathrm{C}$ causes a higher diffusion rate, resulting in domination of $\gamma^{\prime}$-precipitate dynamic reordering over ballistic mixing at the higher temperature. ${ }^{[10]}$ The effect of instability of $\gamma^{\prime}$-precipitate on the plastic deformation mechanisms was explained in our last study on the indentation behavior of room-temperature-irradiated X-750 alloy. ${ }^{[16]}$ It can be briefly mentioned that disordering of the $\gamma^{\prime}$ phase reduces the required shear stress to cut the precipitate by means of diminishing the effect of an antiphase boundary strengthening, which occurs during plastic deformation of the ordered $\gamma^{\prime}$ phase. ${ }^{[33]}$

In addition to the $\gamma^{\prime}$ state, changing the irradiation temperature altered the morphology and distribution of cavities (see Figures 5 through 8). To quantify the effect of changing cavity size and density on mechanical properties, the parameter of cavity spacing was calculated according to Eq. [6] ${ }^{[34]}$ and the results are presented in Table IV.

$$
l=1 / \sqrt{2 r d_{\text {cavity }}} \text {. }
$$

Based on a dispersed hardening model, ${ }^{[35]}$ the stress required to move a dislocation through a field of obstacles increases with decreasing barrier spacing. Therefore, the smaller cavity spacing in $\mathrm{He}-\mathrm{Ni}$ at $400{ }^{\circ} \mathrm{C}$ leads to higher hardness, compared to the $\mathrm{He}-\mathrm{Ni}$ at RT specimen, which is consistent with the indentation results. It should be noted that the cavity spacing obtained for $\mathrm{He}-\mathrm{Ni}$ at $400{ }^{\circ} \mathrm{C}$ and $\mathrm{He}-\mathrm{Ni}$ at $\mathrm{RT}$ samples ( 25 and $38 \mathrm{~nm}$, respectively) is around 2 to 3 times larger than what was reported for helium-implanted $\mathrm{V} / \mathrm{Ag}^{[34]}$ and $\mathrm{Cu} / \mathrm{Nb}^{[26]}$ multi-layered structures. This difference can be attributed to the dramatically higher helium concentrations ( 7 to 10 at. pct) in the multi-layered structures, vs 0.5 at. pct in this study.

Although it is expected that a larger cavity size will be obtained at higher irradiation temperatures, the size distribution curve shows (Figure 8) smaller cavities detected in the $400{ }^{\circ} \mathrm{C}$ irradiated sample, compared to room-temperature irradiation. An in situ study of helium bubble evolution in $\mathrm{SiC}$ thin foil by Beaufort et al. ${ }^{[36]}$ suggests an explanation for this phenomenon. They showed that the size of helium bubbles formed during helium pre-implantation can be reduced as a consequence of subsequent $\mathrm{Au}$ ion irradiation. They suggested that the helium atoms trapped in pre-formed 


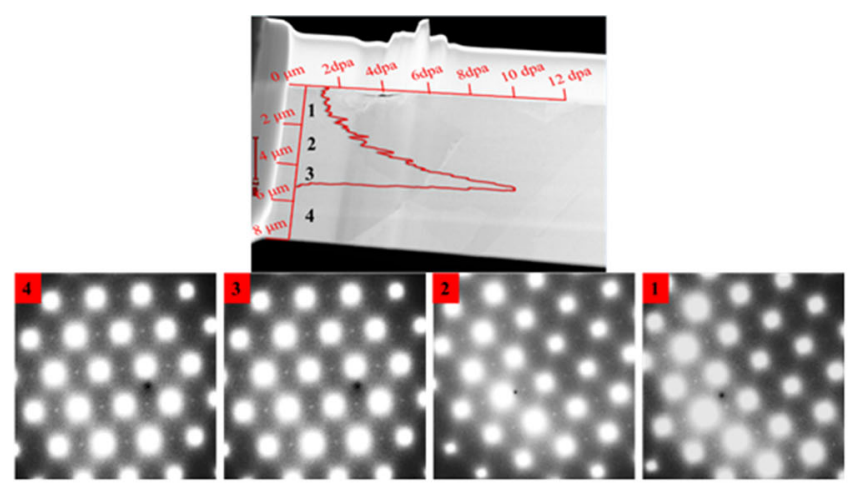

(a)
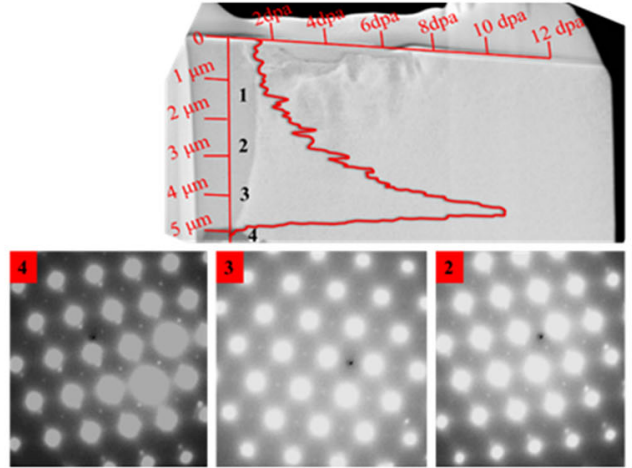

(b)

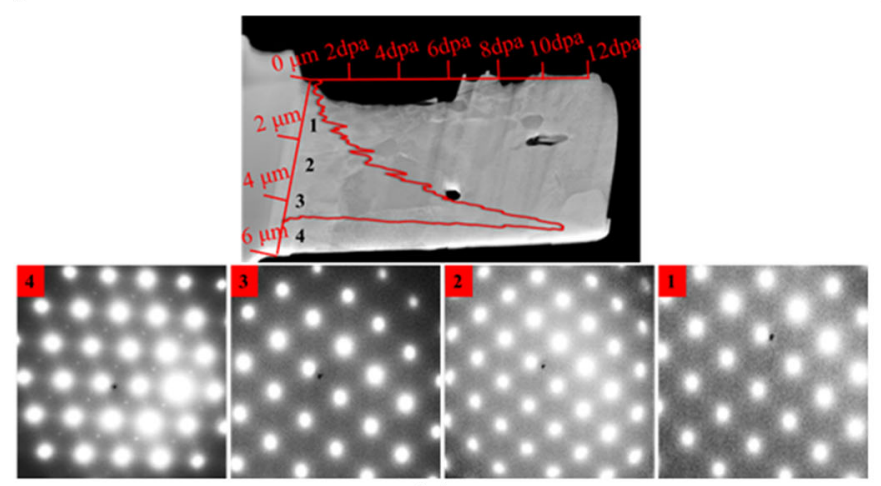

(c)

Fig. $11-$ SADPs at different depths in (a) He-Ni at $400{ }^{\circ} \mathrm{C},(b) \mathrm{Ni}$ at $400{ }^{\circ} \mathrm{C}$, and $(c) \mathrm{He}-\mathrm{Ni}$ at $\mathrm{RT}$ samples.

cavities would be ejected by displacement damage of subsequent ion irradiation, and if the temperature is high enough for diffusion of helium atoms, they will then be re-trapped by irradiation-induced vacancies (at least 50 pct of them), and create many small size cavities, which results in a global reduction of cavity size. Therefore, in accordance with this mechanism, smaller cavity sizes after irradiation at $400{ }^{\circ} \mathrm{C}$ are reasonable. In fact, although ejection of helium atoms from helium implantation-induced cavities happens during subsequent $\mathrm{Ni}$ ion irradiation at both irradiation temperatures, due to the limited helium atom diffusivity at room temperature the ejected atoms are then re-trapped by the same cavities; consequently, the cavity size remains the same as the helium implanted condition during room-temperature irradiation. In contrast, at the higher irradiation temperature of $400{ }^{\circ} \mathrm{C}$, the ejected helium atoms can migrate and be trapped by other vacancies or cavity nuclei and produce several smaller cavities.

The defect characterization by TEM showed that increasing subsequent self-ion irradiation resulted in large-size Frank loops (Table IV), which caused a noticeable hardening effect during the mechanical tests. The growth of Frank loops (which are basically interstitial-type defects), occurs through absorption of free SIAs (self-interstitial atoms). ${ }^{[37]}$ At elevated irradiation temperatures, the diffusion of SIAs is promoted by thermal long-distance diffusion. ${ }^{[11]}$

In summarizing the dependence of irradiation temperature, an increased ion irradiation temperature after helium implantation can change the mechanical response during subsequent nano-scale testing, from a softening to hardening behavior by means of preventing $\gamma^{\prime}$-precipitate disordering, modifying the cavity distribution and morphology, and producing larger irradiation-induced defects.

\section{Analysis of Irradiation-Induced Hardening}

In the following two sections, we have performed nano-indentation results analyzing and correlating them to the bulk mechanical properties of irradiated X-750 alloy, quantifying and distinguishing the impact of each irradiation-induced defect on post-irradiation hardening of experimental material by using obstacle-hardening models.

\section{Nano-hardness and yield strength correlation}

As originally described by Tabor, ${ }^{[38]}$ the indentation made during hardness measurement creates a permanent impression in the material, hence the indentation can primarily measure the plastic and elastic properties of the experimental material. It is seemingly difficult to correlate indentation hardness with bulk mechanical properties, such as uniaxial tensile properties, because of the complicated stress states in the plastic zone of an indent. However, as developed by Busby et al. ${ }^{[39]}$ the nano-hardness measured by indentation test approximately correlates with tensile yield strength according to the following relationship:

$$
\Delta \sigma_{y} \cong 3 \Delta H
$$



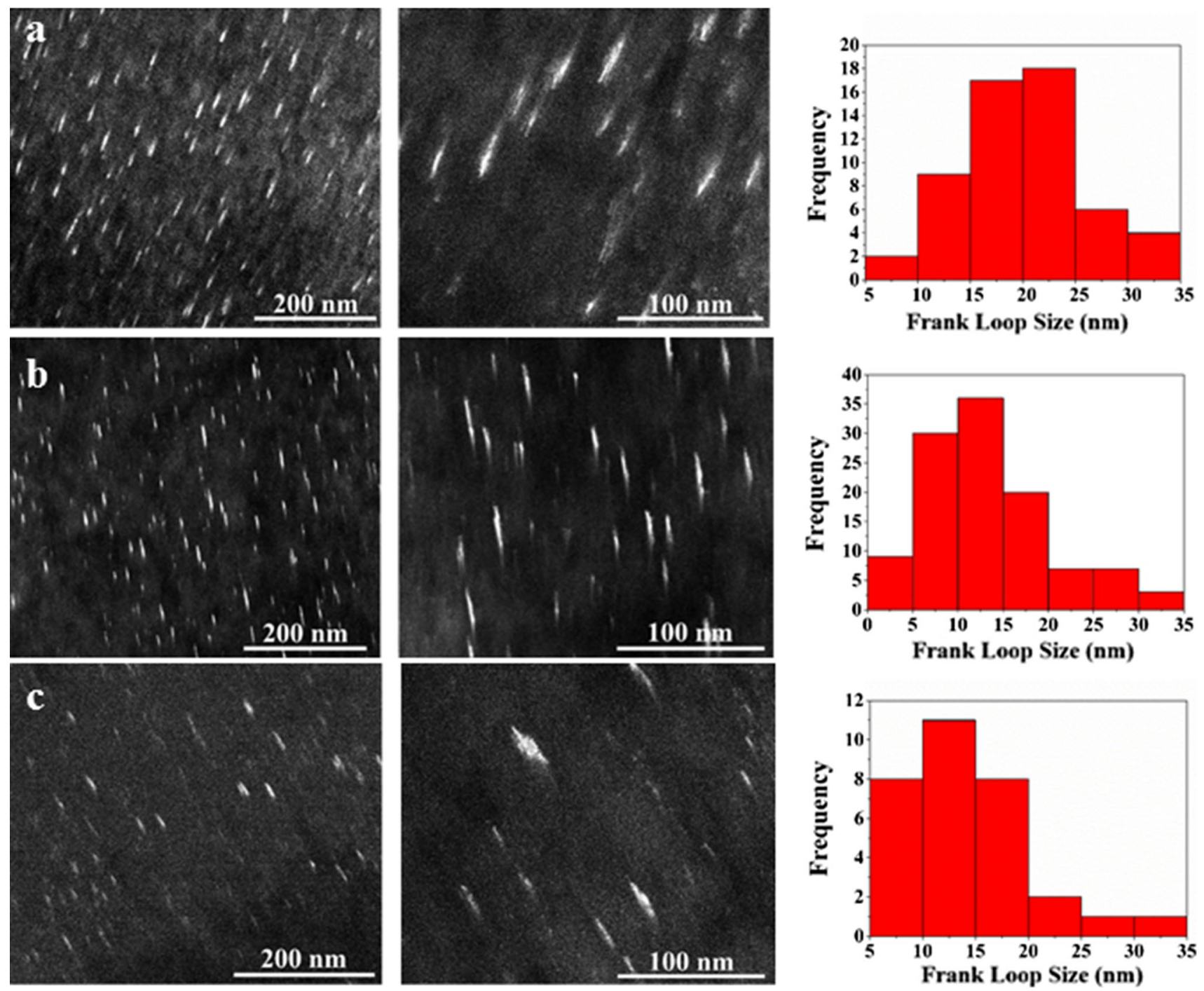

Fig. 12-Irradiation-induced Frank loop distribution in (a) He-Ni at $400{ }^{\circ} \mathrm{C},(b) \mathrm{Ni}$ at $400{ }^{\circ} \mathrm{C}$, and $(c) \mathrm{He}-\mathrm{Ni}$ at $\mathrm{RT}$ samples.

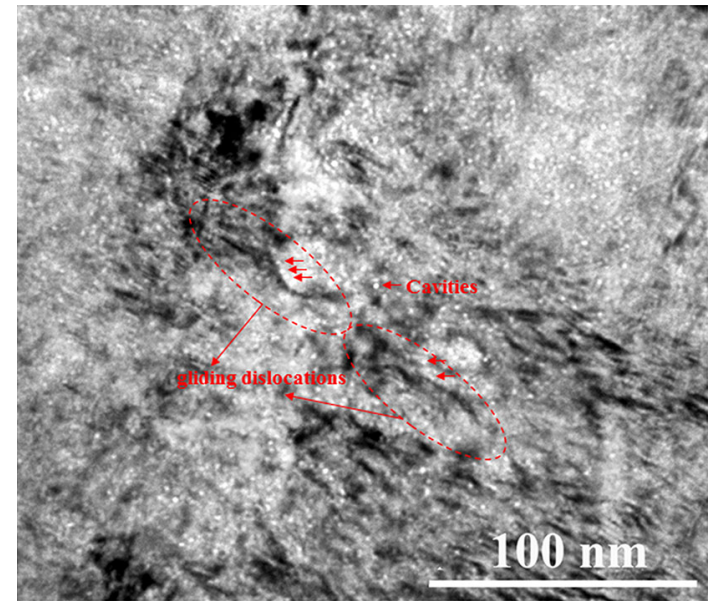

Fig. 13-Bright-field underfocus TEM micrograph, showing the interaction between individual gliding dislocations and irradiation-induced cavities in the plastic zone of indented $\mathrm{He}-\mathrm{Ni}$ at $400{ }^{\circ} \mathrm{C}$ sample. where $\Delta \sigma_{\mathrm{y}}$ is expressed in $\mathrm{MPa}$, and $\Delta H$ is expressed in $\mathrm{Kg} / \mathrm{mm}^{2}$. In order to estimate a changing yield strength with irradiation, a hardness corresponding to a depth of $400 \mathrm{~nm}$ has been taken. The reasons for considering the hardness at a $400 \mathrm{~nm}$ depth are as follows: to make sure that the hardness measurement is carried out in the irradiated depth of sample. If we assume that the plastic zone is 10 times bigger than the actual indent size, ${ }^{[24]}$ then for sampling just at the irradiated depth $(5 \mu \mathrm{m})$ the indentation size should be $<500 \mathrm{~nm}$. In addition, the bigger the indentation size, the smaller the indentation size effect. Therefore, to avoid the effect of significant ISE on the yield strength estimation, the hardness at the $400 \mathrm{~nm}$ depth was chosen. The variations in tensile yield strength obtained after irradiation are presented in Table V. The results show yield strength enhancement of around 382 and $189 \mathrm{MPa}$ for the $\mathrm{He}-\mathrm{Ni}$ at $400{ }^{\circ} \mathrm{C}$ and $\mathrm{Ni}$ at $400{ }^{\circ} \mathrm{C}$ samples, respectively. This reveals the crucial impact of the irradiation-induced defects on the mechanical properties of X-750. However, softening of yield stress in $\mathrm{He}-\mathrm{Ni}$ at RT sample strongly implies that 
Table V. Nano-hardness and Yield Strength Correlation Results

\begin{tabular}{lcc}
\hline Sample & $H_{\text {irradiated }}-H_{\text {Un-irradiated }}(t)$ & $\Delta \sigma_{\mathrm{y}}(\mathrm{MPa})$ \\
\hline He-Ni at $400^{\circ} \mathrm{C}$ & 1.25 & 382 \\
$\mathrm{Ni}$ at $400{ }^{\circ} \mathrm{C}$ & 0.62 & 189 \\
$\mathrm{He}-\mathrm{Ni}$ at $\mathrm{RT}$ & -0.74 & -226 \\
\hline
\end{tabular}

Table VI. Constant Magnitudes Used in Obstacle-Hardening Models

\begin{tabular}{lccccc}
\hline Parameter & $\mu(\mathrm{Pa})$ & $b(\mathrm{~nm})$ & $\alpha$ (Cavity) & $\alpha$ (Frank Loops) & $\alpha$ (Small Defect Clusters) \\
\hline Magnitude & $7.78 \times 10^{10}$ & 0.249 & 0.2 & 0.4 & 0.2 \\
\hline
\end{tabular}

the hardening effect of the defects may be negligible when the strengthening phase, $\gamma^{\prime}$-precipitate, is lost during irradiation. Similar results were found after proton irradiation of Inconel 718, when the reduction in strength occurred due to irradiation-induced dissolution of $\gamma^{\prime}$ and $\gamma^{\prime \prime}$ precipitates; ${ }^{[40]}$ a micro-hardness test on irradiated and un-irradiated materials showed about $245 \mathrm{MPa}$ variation in yield strength $(\Delta H \cong 0.8 \mathrm{GPa})$, which is comparable with our findings for the yield softening after irradiation.

\section{Modeling of irradiation-induced hardening}

Substantial hardening was observed in the post-irradiation mechanical test of $\mathrm{He}-\mathrm{Ni}$ at $400{ }^{\circ} \mathrm{C}$, which was attributed to the effect of irradiation-induced defects on dislocation motion during the mechanical test. In order to understand and quantify the contribution of each type of defect on the irradiation hardening, three different obstacle-hardening models are applied based on microstructural data. In addition, a superposition principle is used to compare the obtained results from each model to the experimental result, and explore the applicability of each model to predict the hardening behavior of X-750 alloy.

The dispersed barrier hardening (DBH) model (Eq. [8]) predicts the yield strength increase caused by arbitrary defects impeding dislocation motion with number defect density $N$, diameter $d$, and glide dislocation Burgers vector magnitude $b .{ }^{[41]}$ This model uses a dislocation line tension approximation and considers all defects within a thin plate to interact with equal obstacle strength with the dislocation.

$$
\Delta \sigma=M \alpha \mu b \sqrt{N d},
$$

where $M$ is the Taylor factor (3.06 for BCC and FCC metals), $\alpha$ is the defect barrier strength, and $\mu$ is the shear modulus.

An alternative hardening model was proposed by Friedel-Kroupa-Hirsch (FKH) (Eq. [9]) and describes material hardening due to the presence of circular dislocation loops of Burgers vector magnitude $b$, diameter $d$, and number density $N^{[42]}$

$$
\Delta \sigma=\frac{1}{8} M \mu b d N^{\frac{2}{3}} .
$$

It should be noted that the dislocation core interactions are not considered in this model even when the dislocation loop lies in the glide path of a straight dislocation. ${ }^{[43]}$

The third model is the Bacon-Kocks-Scattergood (BKS) model (Eq. [10]) which describes the increase in yield strength when there is an infinite array of impenetrable spherical obstacles. The BKS approach develops an obstacle-hardening model, by using the line tension approximation and considering dislocation self-interaction, as well as including the finite size of defects in its formulation.

$$
\begin{array}{r}
\Delta \sigma=\frac{\alpha M \mu}{2 \pi L}\left[\ln \left(\frac{L}{b}\right)\right]^{\frac{-1}{2}}\left[\ln \left(\frac{D^{\prime}}{b}\right)+0.7\right]^{\frac{3}{2}}, \\
L=\frac{1}{\sqrt{N d}}, D^{\prime}=\frac{d L}{d+L}
\end{array}
$$

where $L$ is the mean spacing between obstacles and $D^{\prime}$ is the effective obstacle diameter. The observed irradiation-induced defects in X750 were categorized into three different groups, including cavities, Frank loops, and small defect clusters. The hardening related to each group of defects were calculated based on the three mentioned models, by using the microstructural data and the constants listed in Table VI. ${ }^{[4]}$ The value of $\alpha$ for cavities in Table VI, may appear low at first sight, however, atomistic simulations of the interaction between gliding dislocations and cavities show that the required stress to release an edge dislocation from a small cavity $(\sim 2$ to $5 \mathrm{~nm})$ decreases significantly with increasing helium content within the cavity. ${ }^{[19]}$ The cavity strength at a constant size is dependent upon the number of helium atoms per vacancy $(\mathrm{He} / \mathrm{V})$, and the cavity strength decreases with increasing the $\mathrm{He} / \mathrm{V}$ ratio to $\mathrm{He} / \mathrm{V}=2 \cdot{ }^{[30]}$ Our calculation shows that the number of helium atoms per vacancy in a cavity for most of the samples is lower than 1 . Therefore the strength of the cavities in X-750 alloy is in fact lower than a void. The use of $\alpha=0.2$ was suggested by Lucas ${ }^{[44]}$ in irradiated FCC stainless steel for small helium bubbles.

Figure 14(a) presents the hardening magnitude caused by each obstacle obtained from the $\mathrm{DBH}, \mathrm{FKH}$, and BKS models. Then, the total increase in yield strength can be predicted using the superposition principle to 


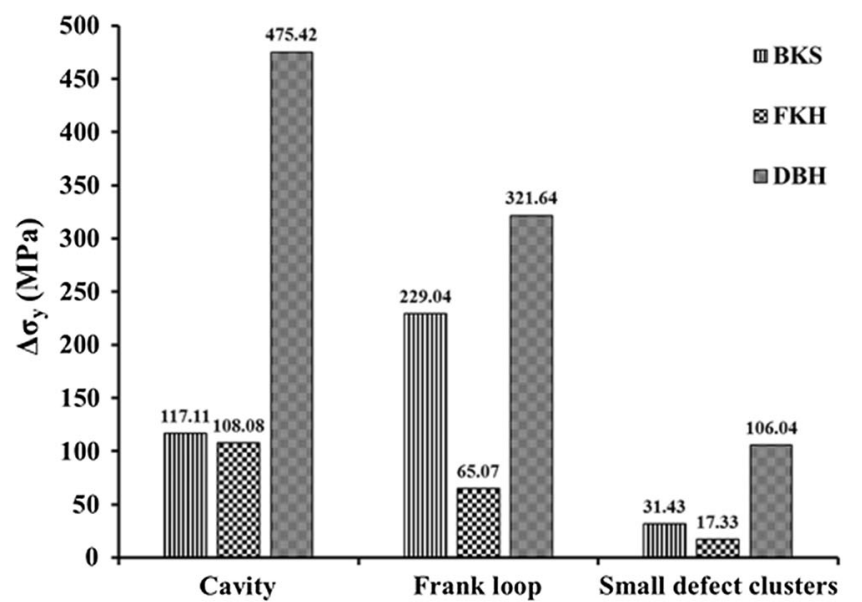

(a)

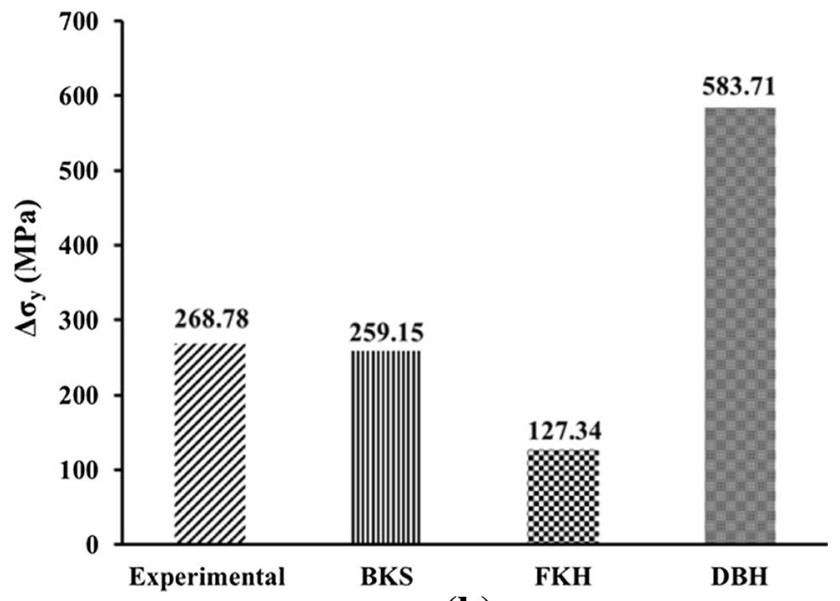

(b)

Fig. 14-The results of obstacle-hardening models showing $(a)$ individual contribution of each type of defects to the irradiation-induced hardening and $(b)$ superposition of each model and comparing to experimental result.

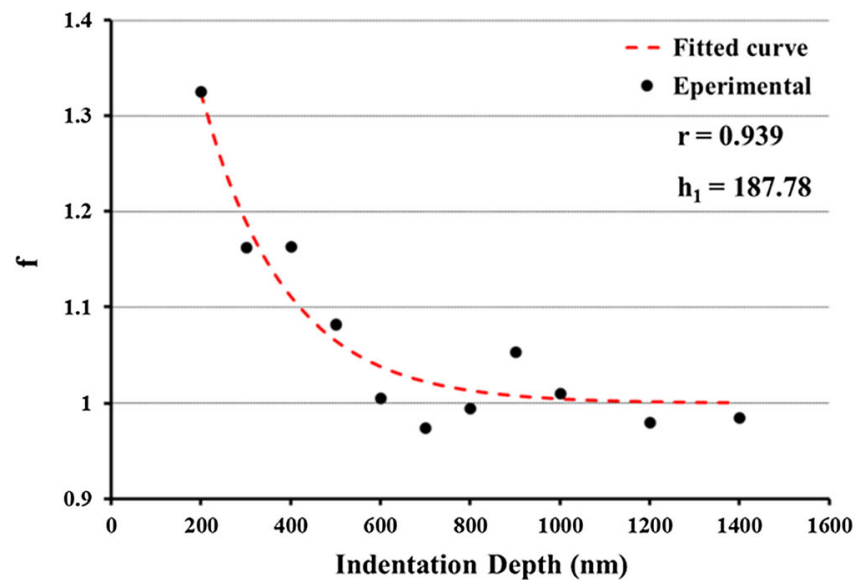

(a)

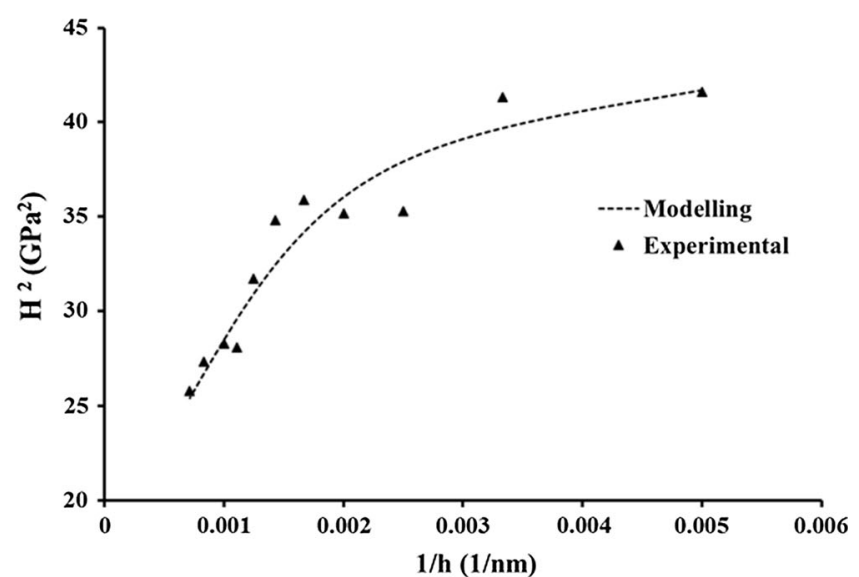

(b)

Fig. 15- (a) Variation of $f$ parameters as a function of indentation depth in un-irradiated material and $(b)$ modeling of indentation size effect using $f$ parameter for un-irradiated material.

combine the independent defect hardening contributions according to Eq. $[8] .^{[45]}$

$$
\Delta \sigma_{\mathrm{T}}^{n}=\Delta \sigma_{\text {Cavity }}^{n}+\Delta \sigma_{\text {Frank loop }}^{n}+\Delta \sigma_{\text {Small defect }}^{n},
$$

where $\Delta \sigma_{\mathrm{T}}$ is the total strength increase, $\Delta \sigma_{i}$ the hardening due to presence of obstacle $i$, and $n$ is a constant, which varies depending on the defect strengths. ${ }^{[43]}$ Assuming $n=2,{ }^{[43}$ the total variation in strength was calculated by computing contributions from each measured defect population individually using $\mathrm{DBH}, \mathrm{FKH}$, and BKS models. Finally, for the sake of comparison, the modeling results and indentation data were plotted in Figure 14(b). The experimental irradiation-induced hardening was assessed using the NG model macroscopic hardness ( $\left.\Delta H=H_{0, \text { irr }}-H_{0, \text { unirr }}\right)$ to eliminate the impact of ISE on hardness measurements. From Figure 14(b), it is immediately clear that under the condition of a variety of defect sizes contributing to the hardening, the DBH model cannot accurately predict the real strength variation. This significant discrepancy can be found when one considers the derivation of the model. It assumes that any defect on the slip plane interacts with equal strength with the dislocation; however, the strength of obstacles strongly depends on the size of the defects. The FKH model is basically developed for weak obstacles to the dislocation motion. According to the analysis from Kocks et al. ${ }^{[46]}$ it is adequate for obstacles with a barrier strength up to $1 / 4$ of the Orowan limit $(\alpha<0.2)$. Therefore, the FKH underestimation of yield strength increase compared to experimental results is reasonable. The best fit for the strength variation due to irradiation was accomplished using a superposition of the BKS model. According to the obtained contribution of each defect type to the irradiation hardening based on the BKS model, the large interstitial Frank loops have the most significant impact on the mechanical property changes, followed by cavities, which play a relatively strong role inducing irradiation hardening. Finally, it was found that smaller defects cause a minor hardening effect on the overall mechanical response of the irradiated X-750. 
While the BKS model can thus be successfully applied to analysis of the mechanical response of the sample irradiated at $400{ }^{\circ} \mathrm{C}$, it is not possible to apply the model to the RT-irradiated sample. This is because of the softening associated with the instability of the $\gamma^{\prime}$ phase under low temperature irradiation, which is not captured by the model described.

\section{ISE in un-irradiated vs irradiated material}

In this section, we will discuss the potential reason for a bi-linear ISE behavior of un-irradiated X-750, and also describe the effect of irradiation-induced defects on changing the ISE trend in the irradiated material. The bi-linear ISE behavior was found for un-irradiated X-750, which shows a shortcoming of the NG model to predict the indentation hardness for the smaller depths. Numerous similar observations have been reported ${ }^{47,48]}$ and two main reasons for the breakdown have been suggested. These include the spreading of the GNDs to a larger plastic zone volume than what the NG model assumes, ${ }^{[48,49]}$ as well as a change in the dominant deformation mechanism at small depths. ${ }^{[50,51]}$ The latter basically proposed that the plastic deformation is controlled by previously established dislocation structures in the micro-regime of indentation; however, the imposed strain is accommodated by source-limited dislocation structures when the deformation volume is small (here less than $600 \mathrm{~nm}$, see Figure 4(a)). The source-limited deformation mechanism has also been observed by Shan et al., ${ }^{[52]}$ through in situ nano-compression experiments inside a TEM during deformation of pure nickel pillars of different sizes. They found a stepwise stress increasing trend rather than continuous increasing, which was attributed to the progressive exhaustion of dislocation sources. Indeed, they showed that if there are enough productive dislocation sources to accommodate the deformation, a stress drop will occur; however, the stress will increase when there are limited dislocation sources, or the pre-existing sources become exhausted. In addition, Rester et al. ${ }^{[5]}$ showed the discrepancy in deformation mechanism between nano and micro-regime indentation in single crystal copper by means of electron backscatter diffraction (EBSD) technique. Their EBSD results indicated that for small indents the orientation changes are very small and no substructure is generated. In contrast, bigger indents corresponding to the higher load, were characterized by substructures that exhibit a large misorientation gradient beneath the indent.

Considering this reason for bi-linear ISE behavior may help us to understand the ISE trend in irradiated material, which was perfectly linear. In fact, irradiation generates dislocation sources by introducing a high density of defects, such as dislocation loops and cavities. Therefore, we speculate that the irradiation-induced defects may act as the productive dislocation sources during indentation that can help to accommodate the indentation strain, particularly at small indentation depths.

One of the strong assumptions in the NG model is that all the dislocations will be confined in a plastic zone with radius equal to contact radius $(a)$, which causes overestimation of the hardness for small indents. It has been found by many other studies that a significant number of dislocations spread out from the plastic zone, due to a strong repulsive force between the dislocations. Hence, in order to relax this assumption and modify the NG model, Feng and $\mathrm{Nix}^{[48]}$ suggested that the plastic zone has an effective radius $\left(a_{\mathrm{pz}}=f a_{\mathrm{c}}\right)$, by introducing function $(f)$ according to Eq. [11].

$$
f=1+r e^{\frac{-h}{h_{1}}}
$$

where $a_{\mathrm{pz}}$ is the plastic zone radius, $a_{\mathrm{c}}$ is the contact radius, $r$ and $h_{1}$ are constants that can be determined by fitting the experimental data. Thus, the NG model can be modified by using function $(f)$ as follows:

$$
H=H_{0}\left(1+\frac{1}{f^{3}} \frac{h^{*}}{h}\right)^{1 / 2} .
$$

For un-irradiated X-750, the indentation experiment data were fitted by this function which resulted in determination of the $r$ and $h_{1}$ constants (Figure 15(a)). The calculated function shows the effect of dislocation spread out on the size of plastic zone. Indeed, when $h=200 \mathrm{~nm}$, then $f=1.32$ which means that the plastic zone radius is 32 pet larger than contact radius. Also, it is clear that for indents larger than $600 \mathrm{~nm}$, the function ( $f$ ) is close to 1 , which is consistent with the point at which we see a change in the linear trend in the NG model (Figure 4(a)). Therefore, Eq. [13] can be found to model the hardness variation as a function of depth for un-irradiated material:

$$
H=H_{0}\left(1+\left(1+0.93 e^{\frac{-h}{187.78}}\right)^{-3} \frac{h^{*}}{h}\right)^{1 / 2} .
$$

Figure 15(b) presents the curve obtained based on Eq. [11], which shows a good fit with the experimental data.

\section{CONCLUSION}

Nano-indentation hardness measurements were carried out to evaluate the mechanical properties of the irradiated X-750 Ni-based superalloy. Two different irradiation procedures were performed; including single self-ion irradiation at $400{ }^{\circ} \mathrm{C}$ as well as self-ion irradiation of previously helium implanted X-750 alloy at both room temperature and $400{ }^{\circ} \mathrm{C}$. Microstructural evolution after irradiation is also traced via cross-sectional TEM observations. The results obtained can be summarized as follows:

1. Prior helium implantation enhanced the irradiation-induced strength increase due to creating a high density of small cavities, promoting generation of larger interstitial defects such as Frank loops.

2. Changing irradiation temperature led to a significant change of the indentation behavior; that is, softening behavior after irradiation at room temperature $v s$ significant hardening after irradiation at 
$400{ }^{\circ} \mathrm{C}$. The TEM observations showed that $\gamma^{\prime}$-precipitate disordering is the main reason for hardness reduction of the room-temperature-irradiated sample.

3. Three obstacle-hardening models were used, based on the observed microstructure data from $\mathrm{He}-\mathrm{Ni}$ at $400{ }^{\circ} \mathrm{C}$ to calculate the individual hardening effect of each type of defect. The results from DBH and FKS models introduced cavities as the strongest barrier; however, the BKS model calculation showed that Frank loops are the main contributor to irradiation-induced hardening, although cavities still provide a significant contribution.

4. The overall hardening based on the superposition principle of each model was also calculated. The results from the DBH and FKS analysis displayed notable over and under estimations, compared to the experimental results. However, a good relationship was obtained from the superposition of the BKS model.

5. The ISE calculations according to NG model showed a bi-linear trend for un-irradiated material; however, a perfect linear behavior was found for irradiated He-Ni at $400{ }^{\circ} \mathrm{C}$. This discrepancy was attributed to the effect of irradiation-induced defects, which act as dislocation sources particularly for indents of smaller size.

6. A modified-NG model was used to find a fit to predict the ISE in the un-irradiated material. The result agreed well with experiment, which overcomes the shortcoming of the NG model to predict the hardness for small indentation sizes.

\section{ACKNOWLEDGMENTS}

Funding for the research was provided by an NSERC/UNENE CRD and the NSERC/UNENE Industrial Research Chair in Nuclear Materials at Queen's University. We would like to thank Professor Sjoerd Roorda and Martin Chicoine at University of Montreal for provision of ion irradiation capabilities. We also thank Chenyang $\mathrm{Lu}$ and Tai $\mathrm{Ni}$ Yang in University of Michigan for assistance with preparing TEM foils via FIB facility.

\section{REFERENCES}

1. C. Sun, M. Kirk, M. Li, K. Hattar, Y. Wang, O. Anderoglu, J. Valdez, B.P. Uberuaga, R. Dickerson, and S.A. Maloy: Acta Mater., 2015, vol. 95, pp. 357-65.

2. G. Sharma, P. Mukherjee, A. Chatterjee, N. Gayathri, A. Sarkar, and J.K. Chakravartty: Acta Mater., 2013, vol. 61, pp. 3257-66.

3. K. Jin, W. Guo, C. Lu, M.W. Ullah, Y. Zhang, W.J. Weber, L. Wang, J.D. Poplawsky, and H. Bei: Acta Mater., 2016, vol. 121, pp. 365-73.

4. F. Long, L. Balogh, D.W. Brown, P. Mosbrucker, T. Skippon, C.D. Judge, and M.R. Daymond: Acta Mater., 2016, vol. 102, pp. 352-63.

5. H.K. Zhang, Z. Yao, G. Morin, and M. Griffiths: J. Nucl. Mater., 2014, vol. 451, pp. 88-96.
6. M. Griffiths, G. A. Bickel, S. A. Donohue, P. Feenstra, C. D. Judge, L. Walters, and M. D. Wright: in 16th International Conference on Environmental Degradation of Materials in Nuclear Power Systems-Water Reactors, Asheville, North Carolina, USA, (2013).

7. M. Griffiths: Nucl. Rev., 2014, vol. 2, pp. 1-16.

8. C.D. Judge, N. Gauquelin, L. Walters, M. Wright, J.I. Cole, J. Madden, G.A. Botton, and M. Griffiths: J. Nucl. Mater., 2015, vol. 457, pp. 165-72.

9. H.K. Zhang, Z. Yao, C. Judge, and M. Griffiths: J. Nucl. Mater., 2013, vol. 443, pp. 49-58.

10. H.K. Zhang, Z. Yao, M.A. Kirk, and M.R. Daymond: Metall. Mater. Trans. A, 2014, vol. 45A, pp. 3422-28.

11. H.K. Zhang, Z. Yao, M.R. Daymond, and M.A. Kirk: J. Nucl. Mater., 2014, vol. 445, pp. 227-34.

12. A.K. Sinha and J.J. Moore: Metallography, 1986, vol. 19, pp. $75-86$.

13. R.S. Nelson, J.A. Hudson, and D.J. Mazey: J. Nucl. Mater., 1972, vol. 44, pp. 318-30.

14. H.C. Liu and T.E. Mitchell: Acta Metall., 1983, vol. 31, pp. 863-72.

15. Y. Huang, M.J. Aziz, J.W. Hutchinson, A.G. Evans, R. Saha, and W.D. Nix: Acta Mater., 2001, vol. 49, pp. 2853-61.

16. P. Changizian, C. Lu, Z. Yao, and L. Wang: Phil. Mag. Lett., 2017, vol. 97, pp. 101-09.

17. K. Farrell: Radiat. Eff., 1980, vol. 53, pp. 175-94.

18. J. Knapp, D. Follstaedt, and S. Myers: J. Appl. Phys., 2008, vol. 103 , p. 013518

19. A. Simar, H.-J.L. Voigt, and B.D. Wirth: Comput. Mater. Sci., 2011, vol. 50, pp. 1811-17.

20. P. Changizian, H. Zhang, and Z. Yao: Phil. Mag., 2015, vol. 95, pp. 3933-49.

21. K. Farrell, P. Maziasz, E. Lee, and L. Mansur: Radiat. Eff., 1983, vol. 78, pp. 277-95.

22. J.F. Ziegler, M.D. Ziegler, and J.P. Biersack: Nucl. Instrum. Methods Phys. Res. B, 2010, vol. 268, pp. 1818-23.

23. W.D. Nix and H. Gao: J. Mech. Phys. Solids, 1998, vol. 46, pp. 411-25.

24. P. Hosemann, D. Kiener, Y. Wang, and S.A. Maloy: J. Nucl. Mater., 2012, vol. 425, pp. 136-39.

25. R. Mills, D. Liebenberg, and J. Bronson: Phys. Rev. B, 1980, vol. 21 , p. 5137

26. N. Li, M. Nastasi, and A. Misra: Int. J. Plast, 2012, vol. 32, pp. 1-16.

27. P. Landau, Q. Guo, P. Hosemann, Y. Wang, and J.R. Greer: Mat. Sci. Eng. A, 2014, vol. 612, pp. 316-25.

28. A. Reichardt, M. Ionescu, J. Davis, L. Edwards, R. Harrison, P. Hosemann, and D. Bhattacharyya: Acta Mater., 2015, vol. 100, pp. $147-54$.

29. L. Yang, X.T. Zu, F. Gao, S. Peng, H.L. Heinisch, X. Long, and R.J. Kurtz: Phys. B, 2010, vol. 405, pp. 1754-58.

30. S.H. Haghighat and R. Schaeublin: J. Comput. Aided Mater. Des., 2007, vol. 14, p. 191.

31. H. Zhang, Z. Yao, M.R. Daymond, and M.A. Kirk: J. Appl. Phys., 2014, vol. 115, p. 103508.

32. S. Zinkle, W. Wolfer, G. Kulcinski, and L. Seitzman: Philos. Mag. $A$, 1987, vol. 55, pp. 127-40.

33. V. Paidar, M. Yamaguchi, D. Pope, and V. Vitek: Philos. Mag. A, 1982, vol. 45, pp. 883-94.

34. Q. Wei, N. Li, N. Mara, M. Nastasi, and A. Misra: Acta Mater., 2011, vol. 59, pp. 6331-40.

35. N. Li, M. Martin, O. Anderoglu, A. Misra, L. Shao, H. Wang, and X. Zhang: J. Appl. Phys., 2009, vol. 105, p. 123522.

36. M.F. Beaufort, M. Vallet, J. Nicolaï, E. Oliviero, and J.-F. Barbot: J. Appl. Phys., 2015, vol. 118, p. 205904.

37. C. Woo and A. Semenov: Philos. Mag. A, 1993, vol. 67, pp. 1247-59.

38. D. Tabor: Br. J. Appl. Phys., 1956, vol. 7, p. 159

39. J.T. Busby, M.C. Hash, and G.S. Was: J. Nucl. Mater., 2005, vol. 336, pp. 267-78.

40. J. Hunn, E. Lee, T. Byun, and L. Mansur: J. Nucl. Mater., 2001, vol. 296, pp. 203-09.

41. A. Seeger: in $I A E A$, Vienna 1962, vol. 1, p. 101.

42. F. Kroupa and P. Hirsch: Discuss. Faraday Soc., 1964, vol. 38, pp. 49-55.

43. C. Sobie, N. Bertin, and L. Capolungo: Metall. Mater. Trans. A, 2015, vol. 46A, pp. 3761-72.

44. G. Lucas: J. Nucl. Mater., 1993, vol. 206, pp. 287-05.

45. U. Lagerpusch, V. Mohles, D. Baither, B. Anczykowski, and E. Nembach: Acta Mater., 2000, vol. 48, pp. 3647-56. 
46. U. Kocks: Mater. Sci. Eng., 1977, vol. 27, pp. 291-98.

47. A. Elmustafa and D. Stone: J. Mech. Phys. Solids, 2003, vol. 51, pp. $357-81$.

48. G. Feng and W.D. Nix: Scripta Mater., 2004, vol. 51, pp. 599-03.

49. J. Swadener, E. George, and G. Pharr: J. Mech. Phys. Solids, 2002, vol. 50, pp. 681-94.
50. M. Rester, C. Motz, and R. Pippan: Acta Mater., 2007, vol. 55, pp. 6427-35.

51. M. Rester, C. Motz, and R. Pippan: Scripta Mater., 2008, vol. 59, pp. $742-45$.

52. Z. Shan, R.K. Mishra, S.S. Asif, O.L. Warren, and A.M. Minor: Nat. Mater., 2008, vol. 7, pp. 115-19. 